\title{
"Only a Life Lived for Others Is Worth Living": Redox Signaling by Oxygenated Phospholipids in Cell Fate Decisions
}

\author{
Yulia Y. Tyurina, Indira Shrivastava,2 Vladimir A. Tyurin,, Gaowei Mao,,3 Haider H. Dar, \\ Simon Watkins, Michael Epperly, Ivet Bahar, Anna A. Shvedova, ${ }^{6,7}$ Bruce Pitt,, Sally E. Wenzel, ${ }^{8-10}$ \\ Rama K. Mallampalli,,9,11 Yoel Sadovsky,2 Dmitry Gabrilovich, ${ }^{13}$ Joel S. Greenberger, \\ Hülya Bayır, and Valerian E. Kagan ${ }^{1,14,15}$
}

\begin{abstract}
Significance: Oxygenated polyunsaturated lipids are known to play multi-functional roles as essential signals coordinating metabolism and physiology. Among them are well-studied eicosanoids and docosanoids that are generated via phospholipase $\mathrm{A}_{2}$ hydrolysis of membrane phospholipids and subsequent oxygenation of free polyunsaturated fatty acids (PUFA) by cyclooxygenases and lipoxygenases.

Recent Advances: There is an emerging understanding that oxygenated PUFA-phospholipids also represent a rich signaling language with yet-to-be-deciphered details of the execution machinery-oxygenating enzymes, regulators, and receptors. Both free and esterified oxygenated PUFA signals are generated in cells, and their cross-talk and inter-conversion through the de-acylation/re-acylation reactions is not sufficiently explored.

Critical Issues: Here, we review recent data related to oxygenated phospholipids as important damage signals that trigger programmed cell death pathways to eliminate irreparably injured cells and preserve the health of multicellular environments. We discuss the mechanisms underlying the trans-membrane redistribution and generation of oxygenated cardiolipins in mitochondria by cytochrome $c$ as pro-apoptotic signals. We also consider the role of oxygenated phosphatidylethanolamines as proximate pro-ferroptotic signals.

Future Directions: We highlight the importance of sequential processes of phospholipid oxygenation and signaling in disease contexts as opportunities to use their regulatory mechanisms for the identification of new therapeutic targets. Antioxid. Redox Signal. 29, 1333-1358.
\end{abstract}

Keywords: oxygenated phospholipids, cardiolipin, phosphatidylethanolamine, apoptosis, ferroptosis, total body irradiation, lipoxygenase, and cytochrome $c$

Reviewing Editors: Catherine Calzada, Thorsten Maier, and Viswanathan Natarajan

Departments of ${ }^{1}$ Environmental and Occupational Health, ${ }^{2}$ Computational and Systems Biology, ${ }^{3}$ Critical Care Medicine, ${ }^{4}$ Cell Biology and Physiology, and ${ }^{5}$ Radiation Oncology, University of Pittsburgh, Pittsburgh, Pennsylvania.

${ }^{6}$ Exposure Assessment Branch/NIOSH/CDC and ${ }^{7}$ Department of Physiology and Pharmacology, West Virginia University, Morgantown, West Virginia.

Departments of ${ }^{8}$ Medicine and ${ }^{9}$ Pulmonary, Allergy and Critical Care Medicine, University of Pittsburgh, Pittsburgh, Pennsylvania.

${ }^{10}$ Asthma Institute, University of Pittsburgh, Pittsburgh, Pennsylvania.

${ }^{11}$ Department of Medicine, Acute Lung Injury Center of Excellence, University of Pittsburgh, Pittsburgh, Pennsylvania.

${ }_{12}^{12}$ Magee Women's Research Institute, University of Pittsburgh, Pittsburgh, Pennsylvania.

${ }^{13}$ The Wistar Institute, Philadelphia, Pennsylvania.

Departments of ${ }^{14}$ Chemistry and ${ }^{15}$ Pharmacology and Chemical Biology, University of Pittsburgh, Pittsburgh, Pennsylvania. 
Table of Contents

I. Introduction

A. Evolution of concepts in oxidative lipidomics

B. LC-MS-based oxidative phospholipidomics: a technological breakthrough

II. Different Signaling Pathways for Nonoxidized and Oxidized CLs in Mitochondria

III. Externalization of Nonoxidized CL Signals Elimination of Damaged Mitochondria

IV. CL Oxidation Signals Apoptosis

V. PS Oxidation Signals Phagocytic Clearance of Apoptotic Cells

1338

VI. Oxidized PEs Signal Ferroptosis

1340

1340

VII. Signaling by Free and Esterified Oxygenated Lipids in Acute Radiation Injury as an Inflammatory Disease: Sequential Engagement of Different Programmed Cell Death Pathways

\section{Introduction}

A MONG THE MANY MEANINGS of Albert Einstein's words quoted in the title-from philosophical to moral, ethical, and emotional-there is a particular one that constitutes the subject of the current special issue and this work, focused on the mechanisms and biological meaning of cell death.

\section{A. Evolution of concepts in oxidative lipidomics}

Lipid molecules represent one of the major constituents of cells and tissues that are soluble in nonpolar organic solvents. One of the major classes of lipids are phospholipids, which have an amphiphilic nature-a combination of a polar watersoluble head with a phosphate moiety and a water-insoluble hydrophobic tail (most commonly two 14-20 carbons long fatty acid chains) linked by glycerol-that allows them to form biomembranes. The two most abundant types of phospholipid molecules in membranes are phosphatidylcholine and phosphatidylethanolamine (PE) complemented with several minor constituents such as phosphatidylserine (PS), phosphatidic acid, phosphatidylglycerol, and diphosphatidylglycerols (or cardiolipins, CL).

Self-assembly of amphiphilic (phospho)lipid molecules into bilayers and semipermeable membrane encapsulation of replicating macromolecules was essential for life from the very early stages of its emergence on the surface of our planet (111). Under anaerobic conditions and high temperatures during that period, saturated and monounsaturated lipids were optimal for building and maintaining the semi-fluid state of membranes in single-cell organisms (35). However, with planet cooling, the appearance of molecular oxygen, and multicellularity, the importance of polyunsaturated lipids surpassed a structural building block role and now includes vital functions as communication molecules required for coordination of multiple processes into spatiotemporally integrated and optimized forms of life (58).

Based on fossil records, there was a major change in the propagation of life that abruptly occurred $\sim 600$ million years ago, when the oxygen content in the atmosphere became sufficient for the maintenance of aerobic life (21). All land-based mammals had access to sufficient nutrient resources judged by their large body mass and fast growth rates they attained (99). Archaeological data indicate that sufficiency of food enriched in long-chain polyunsaturated fatty acids (LC-PUFA) was essential for sustaining the large size, complexity of the modern human brain. LC-PUFA were also essential for multi- generational brain development, thus contributing to the advent of Homo sapiens (60). Notably, contemporary evolutionary models emphasize that proximity to marine, lacustrine, and riverine sources of food and utilization of littoral resources with high levels of LC-PUFA by Homo during the period 20-200 kya was critically important for the development of the human brain (13). Today, dietary essential long-chain fatty acid residues (C20, C22) with four, five, and six double bonds remain the most limiting nutrients for brain lipids and neural growth $(20,22-24,59)$. The reasons for the critical dependence of brain development and functions on these LC-PUFA still remain unknown. However, a popular concept that PUFA lipids are essential for the maintenance of biomembranes fluidity is generally accepted, in spite of the fact that oleic acid (C18:1) residues are sufficient for keeping membranes fluid enough.

One of the important chemical propensities of polyunsaturated lipids is their susceptibility toward oxygenation (39). Enzymatically, these reactions are catalyzed by a host of monoand di-oxygenases yielding myriads of highly diversified and versatile functions. Among these functions, signaling by oxygenated derivatives of free PUFA has attracted much attention as regulators of intracellular metabolism and intercellular communications (86). Numerous functions of octadecanoids, eicosanoids, docosapentanoids, and docosahexanoids mediated by their specialized receptors have been identified in health and disease $(27,109,115)$. Different phospholipids with esterified PUFA-FA residues undergo hydrolysis by phospholipases $\mathrm{A}-\mathrm{a}$ rate-limiting enzymatic process that releases PUFA for subsequent oxygenation steps catalyzed by one of several enzymes such as cyclooxygenase, lipoxygenases (LO), and cytochromes P450 (49, 78, 114, 124, 160). These concepts peacefully accommodate current knowledge about important lipid mediators and their precursors PUFA-phospholipids.

For a long time, oxygenation of PUFA residues of phospholipids has been predominantly associated with structural organization of biomembranes, mostly in the context of oxidative damage $(165,166)$. Initiated by the interest to radiation-induced injury and free radicals produced during radiolysis of water $(8,142)$, the chemical concepts of liquid phase oxidation have been transferred to biology and gave birth to new interdisciplinary fields of research-free radical biology and medicine. For more than five decades, the concepts of free radical-induced damage of membranes caused by poorly controlled random free radical oxidation of polyunsaturated phospholipids dominated the field and triggered the high interest to small-molecule chemical scavengers of 
radicals, that is, antioxidants $(28,112,149)$. A simple and readily accepted concept of oxidative stress-a disbalance of endogenous antioxidant/prooxidant systems in favor of the latter-encouraged numerous, initially optimistic, studies aimed at the compensation of endogenous antioxidant deficiency in essentially all major human diseases and in aging $(55,139,140)$. Disappointingly, the enthusiasm associated with the use of antioxidants did not withstand the rigorous scrutiny of multiple clinical trials, which consistently demonstrated the lack of therapeutic efficacy of exogenous natural or chemically designed antioxidants $(107,108,147,150,167)$.

\section{B. LC-MS-based oxidative phospholipidomics: a technological breakthrough}

The new wave of interest in oxidative reactions of polyunsaturated phospholipids paralleled the advancement of smallmolecule mass spectrometry (MS), associated with mild ionization, particularly electrospray, technologies (38). The discovery of a remarkably rich and diverse (phospho)lipidome and multiple signaling functions of phospholipids inspired research in the field of MS-based oxidative phospholipidomics $(76,121,145)$. The enormous diversity of nonoxidized lipids is sufficient to constitute a significant component of metabolomics. Oxidative modification of PUFA lipids increases the number of their molecular species by at least an order of magnitude, thus making lipids dominant in the metabolome. This is mainly due to positional distribution of several oxygencontaining functionalities-hydroperoxy-, hydroxy-, oxo-, and epoxy - after oxygenation of bis-allylic carbon atoms at different positions in the PUFA residues (27) as well as oxidative truncation of the hydroperoxy-derivatives yielding the products with a shortened side chain (Fig. 1).

In spite of the huge variety of the oxygenated (phospho)lipids in terms of the molecular speciation, their absolute amounts are usually very low, on the order of $0.1-3.0 \mathrm{~mol} \%$ of total nonoxidized phospholipids. Thus, identification and quantitative characterization of LC-MS-based protocols of phospholipid oxidation products is challenging, particularly in a nontargeted approach aimed at maximizing detection of all diversified species for subsequent identification of those that are associated with a particular function of interest. In spite of significant technical difficulties, partly also caused by the lack of standards for the majority of individual oxidized phospholipids, their semi-quantitative comparative analysis permits obtaining valuable and biologically interpretable data. The analytical task becomes much easier when targeted quantification of a partial list ("inclusion list") of oxygenated phospholipids is required. Finally, it should be mentioned that many of the oxygenated phospholipid species are highly electrophilic and can readily
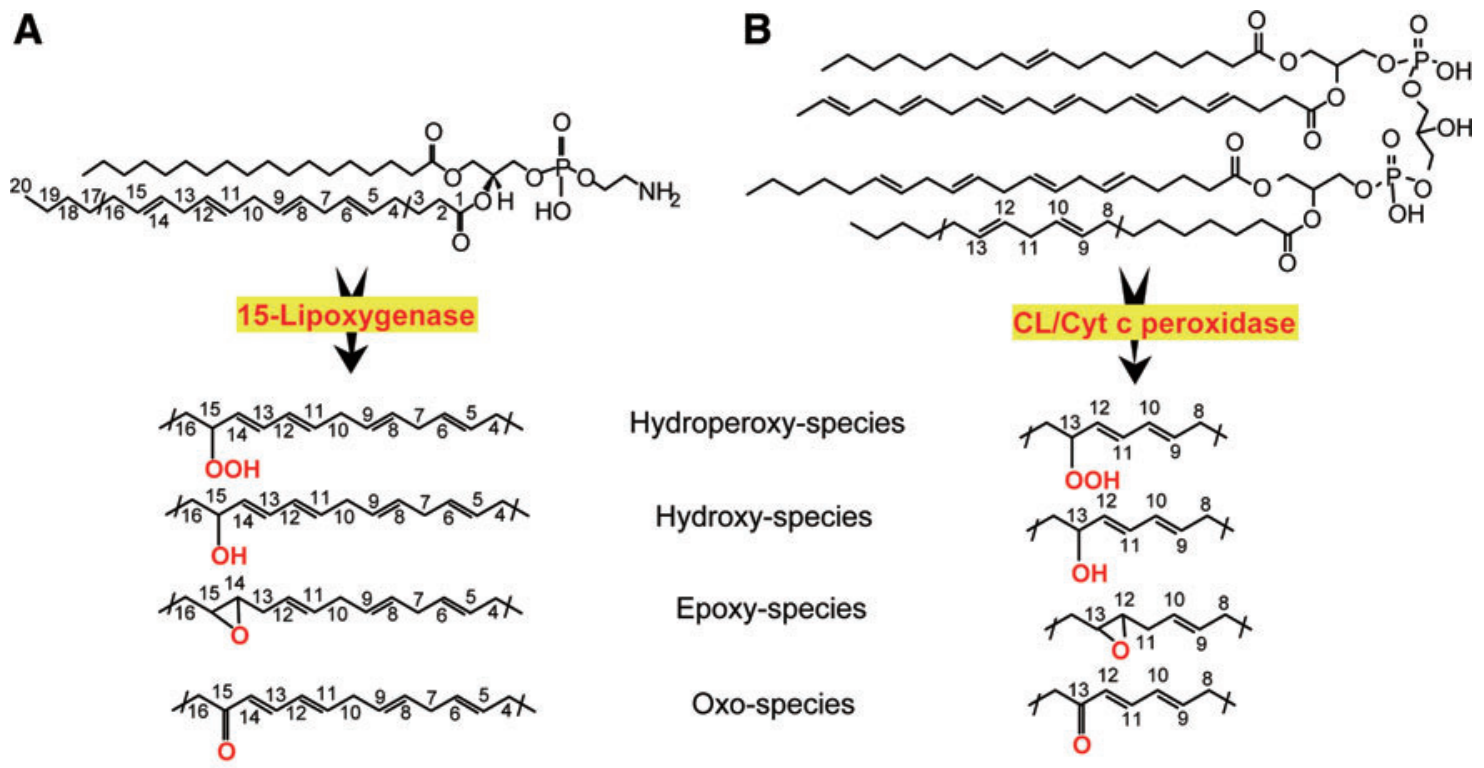

Hydroperoxy-species

Hydroxy-species

Epoxy-species

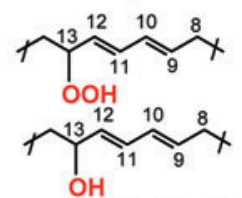

$\mathrm{OH}$

Oxo-species
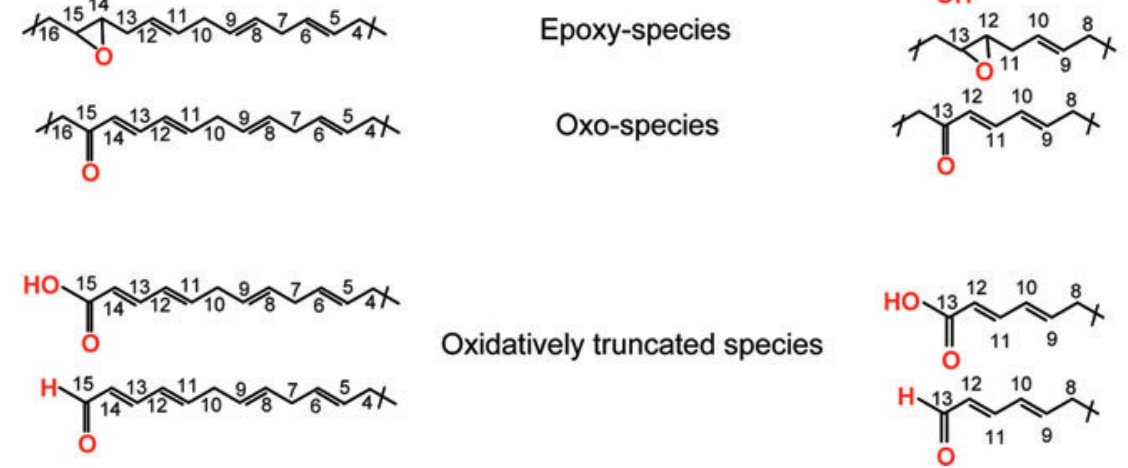

FIG. 1. Enzymatic catalysis of oxidation of two polyunsaturated phospholipids, resulting in the signal formation. (A) 15-LO catalyzes oxidation of AA-PE to yield ferroptotic death signals. AA-OOH-PE is produced as the primary molecular product that can be subsequently reduced to respective hydroxy-derivatives or converted into epoxy-, oxo-, or oxidatively truncated electrophilic products with shortened side chains. (B) cyt $c / C L$ peroxidase complex oxidizes linoleic acid residue in hetero-acylated CL to yield linoleoyl hydroperoxy-CL, hydroxy-, epoxy-, oxo-, or oxidatively truncated electrophilic products with shortened side chains. 15-LO, 15-lipoxygenases; AA-PE, arachidonoyl-phosphatidylethanolamine; AA-OOH-PE, 15hydroperoxy-AA-PE; CL, cardiolipin; cyt $c$, cytochrome $c$. To see this illustration in color, the reader is referred to the web version of this article at www.liebertpub.com/ars 
form adducts by reacting with nucleophilic sites of proteins (33, 159). These adducts may represent the most functionally important products whose formation is responsible for the signaling effects. Thus, the new direction of research and technology advancement demands the development of oxidative proteo-lipidomics $(17,101,144)$. Obviously, technological difficulties of this endeavor may be even greater due to multiplicity and even a greater variety of covalent complexes of myriads of electrophilic phospholipid oxidation products with thousands of target proteins.

\section{Different Signaling Pathways for Nonoxidized and Oxidized CLs in Mitochondria}

The presence of life-sustaining atmospheric oxygen content in the atmosphere for the maintenance of aerobic life based on fossil records occurred $\sim 600$ million years ago. This created a new universal intracellular instrument organelle, mitochondria, and caused significant changes in the forms of life (21). As a thermodynamically open system of eukaryotic cells - from protozoan to mammals-mitochondria produce and exchange energy, metabolites, and information. They are filled with the machinery for oxidative metabolic reactions coupled with electrochemical generation of membrane potential and leading to the production and preservation of energy in the form of ATP $(18,36,143)$. (18, 36, 143). In addition to being the major powerhouse of cells, mitochondria also act as a regulatory hub and are involved in the coordination of multiple intra- and extracellular processes and in controlling cell death (41). Interestingly, many regulatory functions of mitochondria are associated with their unique and asymmetrically distributed phospholipid, CL (122) (Fig. 2).

Chemically, CLs represent an unusual dimeric molecule with an anionic doubly charged (with two phosphate groups) polar head and a highly hydrophobic body with four fatty acyls linked via glycerol moieties. In contrast to other phospholipids, CLs are synthesized exclusively in mitochondria $(56,98,128)$ by CL synthase on the matrix side of the inner mitochondrial membranes (IMM) (131) and can undergo subsequent postsynthetic remodeling $(129,130)$. The remodeling process is believed to generate homoacylated-with four identical fatty acid residues, most commonly C18:2-CL species in some tissues (heart, skeletal muscles, liver) $(56,113,123,132)$, in contrast to highly diversified hetero-acylated CLs in most tissues, particularly in the brain $(12,81,154)$. Overall, the majority of CL species in mammalian cells contain one or more PUFA and, hence, are readily oxidizable $(92,125)$.

\section{Externalization of Nonoxidized CL Signals Elimination of Damaged Mitochondria}

Electron transport and other redox functions of the mitochondrial respiratory chain and enzymatic machinery are

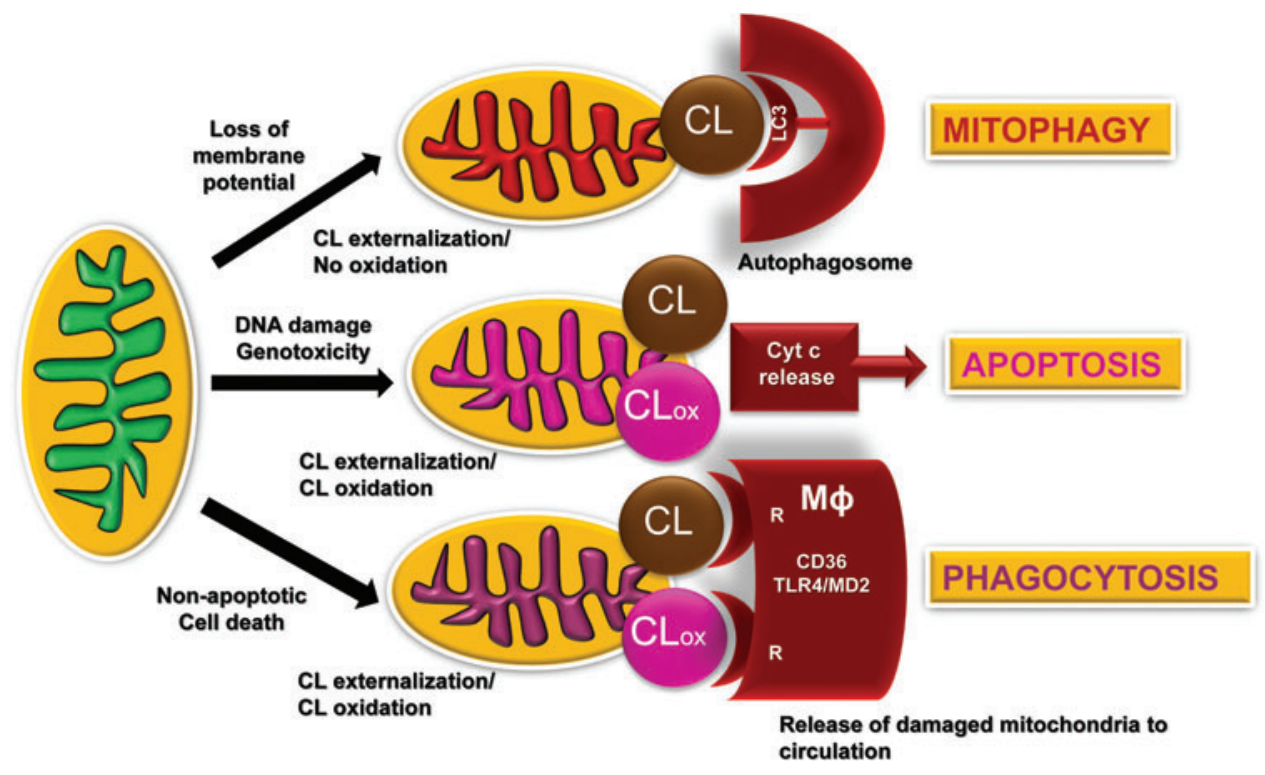

FIG. 2. Schema illustrating the signaling mechanisms for externalized and oxidized CL in mitochondria, extramitochondrial and extra-cellular compartments. Damage to mitochondria resulting in IMM depolarization triggers the process of CL externalization to the mitochondrial surface whereby CL is recognized by one of the major components of the autophageal machinery, LC3. This process of CL redistribution from the IMM to the OMM and binding of CL with LC3 initiates mitophagy of injured mitochondria, and it is important for the mitochondrial quality control. Successful removal of damaged mitochondria serves a pro-survival function and maintains normal cell metabolism. If mitochondrial injury exceeds the reparative capacities of a given cell (e.g., excessive DNA damage), redistribution of CLs to the OMM creates conditions for its interaction with an intermembrane space hemoprotein, cyt $c$ to yield a complex with a peroxidase catalytic competence toward PUFA-CL. CLox acts as a pro-apoptotic signal facilitating release of cyt $c$ from mitochondria into the cytosol, thus designating a point of no-return in the execution of the intrinsic apoptotic program. Damaged mitochondria and/or their fragments with externalized CL and CLox are recognized by CD36-driven mechanisms of professional phagocytes, thus leading to their elimination by macrophages. Externalized CL (and CLox) may also interact with the MD2/TLR4 system on the surface of macrophages, leading to silencing of cytokine production and immune-paralysis. CL, cardiolipin; CLox, oxidized CL; IMM, inner mitochondrial membranes; LC3, light chain 3; MD2, myeloid differentiation protein 2; OMM, outer mitochondrial membrane; PUFA, polyunsaturated fatty acids; TLR4, toll-like receptor 4 . To see this illustration in color, the reader is referred to the web version of this article at www.liebertpub.com/ars 
conducive of one-electron transfer reactions, including the reduction of molecular oxygen and thus generating superoxide anion-radicals and $\mathrm{H}_{2} \mathrm{O}_{2}(91)$. Discoordination of these reactions may lead to excessive production of reactive oxygen species (ROS), potentially leading to injury of the affected mitochondria, and other intra- and extracellular targets. To avoid the calamitous consequences of these redox misfortunes, a mitochondria-specific type of autophagy, mitophagy, is usually activated to eliminate the dysfunctional organelles, thus representing a pro-survival mechanism (51, 174). Notably, mitochondrial membrane depolarization caused by the excessive production of ROS is not the only trigger of mitophagy. In particular, superoxide anion radicals, one electron reduction product of oxygen, are not effective modifiers of mitochondrial membranes. However, their dismutation product-formed spontaneously or catalytically wih the participation of $\mathrm{Mn}-\mathrm{SOD}-\mathrm{H}_{2} \mathrm{O}_{2}$ may act as a source of oxidizing equivalents for the peroxidase function. In this regard, cytochrome $c$ (cyt $c$ )/CL complex may play a role of a very potent membrane modifier that is specific for $\mathrm{CL}$ oxidation $(77,79)$.

Oxidation of CL is associated with the loss of membrane potential in mitochondria (141). For example, treatment of cells with protonophoric uncouplers, such as carbonyl cyanide-ptrifluoromethoxyphenylhydrazone (FCCP), also initiates mitophagy of depolarized mitochondria (16). Importantly in the context of this work, these pro-mitophageal stimuli cause a collapse of mitochondrial asymmetry of CL confinement to the IMM and trigger its redistribution to the outer mitochondrial membrane (OMM) and externalization to the surface whereby the unusual phospholipid is recognized by microtubule-associated protein 1 light chain 3 (LC3) (Fig. 2), one of the major components of the autophageal equipment of cells (16). The recognized signal with the attached cargo stimulates the inclusion of the damaged mitochondria in the autophagosome for further digestion and elimination. Binding with LC3 is mostly driven by electrostatic interactions of positively charged basic patches of the protein, particularly $\mathrm{N}$-terminal residues $\mathrm{R}_{10}$ and $\mathrm{R}_{11}$, with two CL's negatively charged phosphate groups (16). Although the presence of all four acyls in CL is essential for its binding to LC3, the overall mitophagy process does not display any preference for individual fatty acid residues. The mitophageal signaling by externalized CL is not associated with the oxidation of the PUFA residues in the phospholipid $(15,16,72)$.

The central event in mitophageal signaling by CLs is the collapse of its membrane asymmetry and redistribution from the IMM to the OMM. The complete network of enzymatic mechanisms fulfilling this function remains enigmatic. Given that CLs are synthesized on the inner leaflet of the IMM and interact with LC3 after their appearance on the outer leaflet of the OMM, one can envision the necessity of three discrete translocations: within the IMM, between the IMM and OMM, and within the OMM (Fig. 3). As CL molecules include a bulky hydrophobic body and a doubly charged head, the travel through and in between two membrane surfaces is associated with significant energetic expenditures.

Currently, only one of the proteins involved in the CL transfer between the IMM and OMM has been identified-a mitochondrial isoform of nucleoside-diphosphate kinase D (NDPKD) (Fig. 4) $(74,134)$. A well-known function of the enzyme is the transfer of phosphate groups between different nucleosides such as ATP $>$ GDP, thus providing a pool of available GTP for mitochondrial GTPases (e.g., OPA1) (134). NDPK-D has been known to bind and transfer CLs between donor and acceptor liposomes (87). More detailed studies including LC-MS-based identification of molecular species of CLs in the IMM and on the mitochondrial surface revealed engagement of the hexameric protein in the process of CL externalization $(74,133)$. The CL-binding site includes $\mathrm{R}_{90}$ as the mutated protein product $\mathrm{R}_{90} \mathrm{~A}$ lacked the binding and transporting capacity (74). Computational assessments of ligand binding energies suggest that the affinity of NDPK-D for CL is relatively low. This may be an important mechanism to preclude "excessive" sensitivity to fluctuations of free CL content in the IMM. The CL-

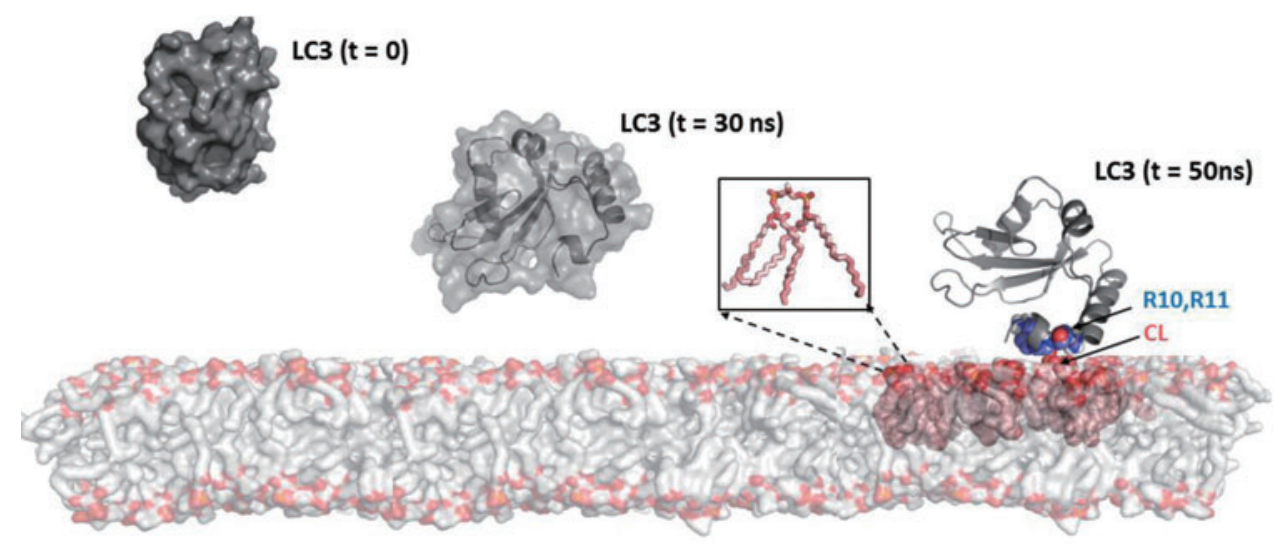

FIG. 3. A model of interaction of microtubule-associated-protein-1-LC3 with CL integrated into the lipid bilayer. Model of a bilayer made up of DOPC (shown as gray surface) and CL molecules are illustrated as pink spheres, with headgroups colored orange. The protein LC3 is shown at different intervals ( $t=0,30$ and $50 \mathrm{~ns})$. At $t=0 \mathrm{~ns}$, the van-der Waal's surface of the protein is shown; at $t=30 \mathrm{~ns}$, the secondary structures are shown in ribbon diagram, enclosed within the vander-Waal's surface; and at $t=50 \mathrm{~ns}$, the residues interacting with CL (R10 and R11) are highlighted in space-filling representation. The inset shows details of a single CL molecule with acyl chains in pink and the head-group in orange. The details of the LC3-CL interactions are available in Chu et al. (16). DOPC, 1,2-dioleoyl-sn-glycero-3-phosphocholine. To see this illustration in color, the reader is referred to the web version of this article at www.liebertpub.com/ars 


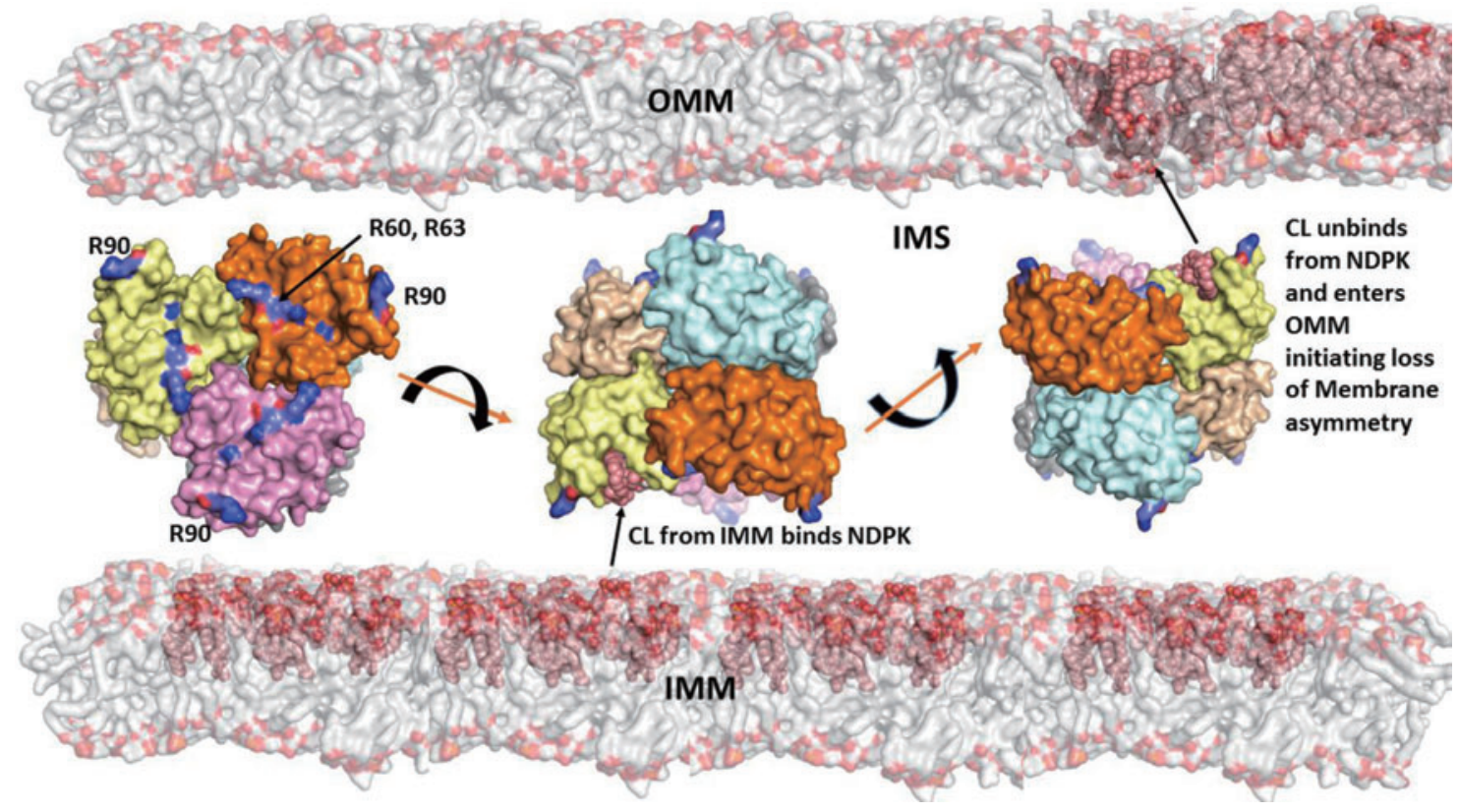

FIG. 4. A model illustrating different stages of externalization of CL from the IMM to the OMM, including the CL transfer through the intermembrane space by NDPK-D. Hexameric complexes of NDPK-D consist of monomers colored in six different colors. Shown also are R90-containing sites involved in binding of CLs. Model of a bilayer made up of DOPC (shown as gray surface) and CL molecules are illustrated as pink spheres, with head-groups colored orange. The van-der-Waal's surface of hexameric protein NDPK is shown in the IMM at different positions. The conserved arginine residues implicated in binding of CL are labeled and highlighted in the leftmost hexamer (134). The asymmetry in the CL distribution in IMM and OMM is indicated by highlighting the CL, with its higher content in IMM versus OMM, before release of CL from the CL-NDPK complex (rightmost hexamer). NDPK-D, nucleoside-diphosphate kinase D; PE, phosphatidylethanolamine. To see this illustration in color, the reader is referred to the web version of this article at www .liebertpub.com/ars

dependent NDPK-D-mediated pathway, thus, may be an effective pro-survival factor, and in a number of episodes injury alternative signaling machineries may be triggered.

Several distinct receptors participating in the mitophageal process have been characterized (50). Among them are a ubiquitin-binding domain that localizes them to Parkinubiquitinylated mitochondria, including p62/SQSTM1, NBR1, and optineurin whereby Parkin binds AMBRA1 to localize it at the OMM. Another group of mitophagy receptors operates by engaging Bnip3, its homologue Bnip3L/Nix, FUNDC1, and Bcl2L13 (50). These mitophagy receptors have transmembrane domains that constitutively localize to the OMM. It is possible that CL externalization may be involved, at least in part, in realization of these alternative processes for maintenance of mitochondrial and cell health. In lieu of this, it is tempting to speculate that the recruitment and redistribution of some of these molecules into mitochondria (e.g., PINK1) may be associated with the presence of externalized CL on the mitochondrial surface. Finally, it is worth noting that CL externalization in mammalian mitochondria may reflect a more ancient mechanism that is also employed by prokaryotes. Indeed, in interactions of gram-negative bacteria with the target/host cells, bacteria externalize their CLs from the inner membranes to the surface (25).

\section{CL Oxidation Signals Apoptosis}

Successful and effective elimination of damaged mitochondria via mitophagy may be sufficient for the protection of the injured cell from the risk of continuously spreading of damage. However, the failure of the cell to cope with the accumulating damage and (geno)toxicity via activation of repair processes, including DNA repair, necessitates the next elimination step-initiation of apoptosis, commonly via activation of $\mathrm{p} 53$-dependent mechanisms operating via mitochondria-dependent pathways $(10,85)$. This "sacrificial" behavior is particularly important for the protection of the entire cell community from possible release of dangerous factors, leading to uncontrolled spreading of the toxic impact.

When mitochondrial CLs are no longer confined to the IMM and have re-distributed into the OMM, they have essentially unlimited access to the intermembrane space components, including a mobile electron carrier, the small hemoprotein cyt $c$ (126). Usually, the latter shuttles electrons between respiratory complexes III and IV, a function to which it is ideally adapted due to full occupancy of its coordination bonds $(54,169)$. Indeed, hexa-coordinated arrangement of the heme-iron in cyt $c$-with tetra-coordination by the heme and two axial ligands, $\mathrm{Met}_{80}$ and $\mathrm{His}_{18}$ - precludes its unwanted capacities for a peroxidase-like catalysis.

Readily available CLs bind cyt $c$ and change its coordination state by loosening heme-Fe-S bonding with Met ${ }_{80}$, thereby permitting the access for the pro-oxidant small molecules, such as $\mathrm{H}_{2} \mathrm{O}_{2}$, to act as a source of oxidizing equivalents and induce peroxidase competence of cyt $c(6$, $11,100,105)$. Radical migration from the porphyrine ring of the heme, typical for the peroxidase catalysis mechanism, occurs also in the cyt $c / C L$ complexes whereby the formation 
of oxo-ferryl species $\left(\mathrm{Fe}^{4+}=\mathrm{O}\right)$ takes place at the expense of the electron withdrawal predominantly from its proximity to the heme-Fe, $\operatorname{Tyr}_{67}(77,80)$. The targets for the enzymatic oxidative attack by the peroxidase activity of cyt $c / \mathrm{CL}$ complex are PUFA residues of CLs (77). Accumulation of oxygenated forms of CL (CLox) in the OMM facilitates the release of cyt $c$ from mitochondria into the cytosol, defining a point of no return in the apoptotic program (Fig. 5, left panel). Given recent evidence that formation of cyt $c / C L$ complexes is important for the OMM permeabilization and the release of the hemoprotein from mitochondria into the cytosol (82), it is possible that $\mathrm{CL}$ oxidation facilitates this process.

The participation and essentiality of selective CL oxidation as a required mitochondrial stage of intrinsic apoptotic program has been demonstrated for many different types of wild-type cells. As expected, genetic manipulations causing deficiency of either CL-synthase as well as the entire cyt $c$ or mutation of its $\operatorname{Tyr}_{67}$ residue suppressed the apoptotic responses $(5,9,62,95,97)$. Moreover, in several in vivo models with characteristic massive apoptotic death, such as hyperoxia in mice, inhalation exposure to single-walled carbon nanotube in mice, total body irradiation (TBI) in mice, and traumatic brain injury in "pediatric" rats-the accumulation of $\mathrm{CL}$ oxidation products has been confirmed by quantitative LC-MS-based oxidative lipidomics analysis (12, 65, 153, $156,158)$.

The importance of CLox accumulation as a pathogenic mechanism has been confirmed by the protective effects of several mitochondria-targeted inhibitors of $\mathrm{CL}$ oxidation
$(7,37,66,69,119,148)$. Among them, a series of newly developed electron scavengers (XJB-5-125, XJB-5-131, JP4039) capable of preventing the formation of $\mathrm{H}_{2} \mathrm{O}_{2}$ as a source of oxidizing equivalents for the cyt $c / C L$ catalyzed reactions were very effective (Fig. 6) $(37,66,119)$. Another group of effective regulators includes imidazole-substituted fatty acids whereby strong liganding of the imidazole group with the heme-Fe prevented its further participation in the catalysis of the peroxidase CL oxidation (Fig. 6) and protected against radiation-induced apoptosis in vivo (7).

As an enzymatic oxidation reaction, cyt $c$ catalyzed oxidation of PUFA CLs is expected to display specificity toward different molecular species of phospholipids. Assessments of the specificity are complicated by the multiplicity of the products formed concomitantly in several reactions of CL oxidation during the same incubation, even in relatively simple biochemical systems (Fig. 7).

The evaluation of the CL oxidation specificity is difficult in cultured cells and even more complex in animal tissues, where a heterogeneous cell population such as inflammatory cells and professional phagocytes affect specific pro-oxidant features of the microenvironment and also clear injured and dying cells. Amazingly, in spite of all these potentially strong confounding factors, features of remarkable selectivity in the molecular speciation of $\mathrm{CL}$ oxidation products can be revealed. For example, after traumatic brain injury, oxidation products in hetero-acylated CL species containing C22:6, $\mathrm{C} 20: 4$, and C18:2 residues were detected. The rules of random chemical oxidation predict that the most polyunsaturated FA
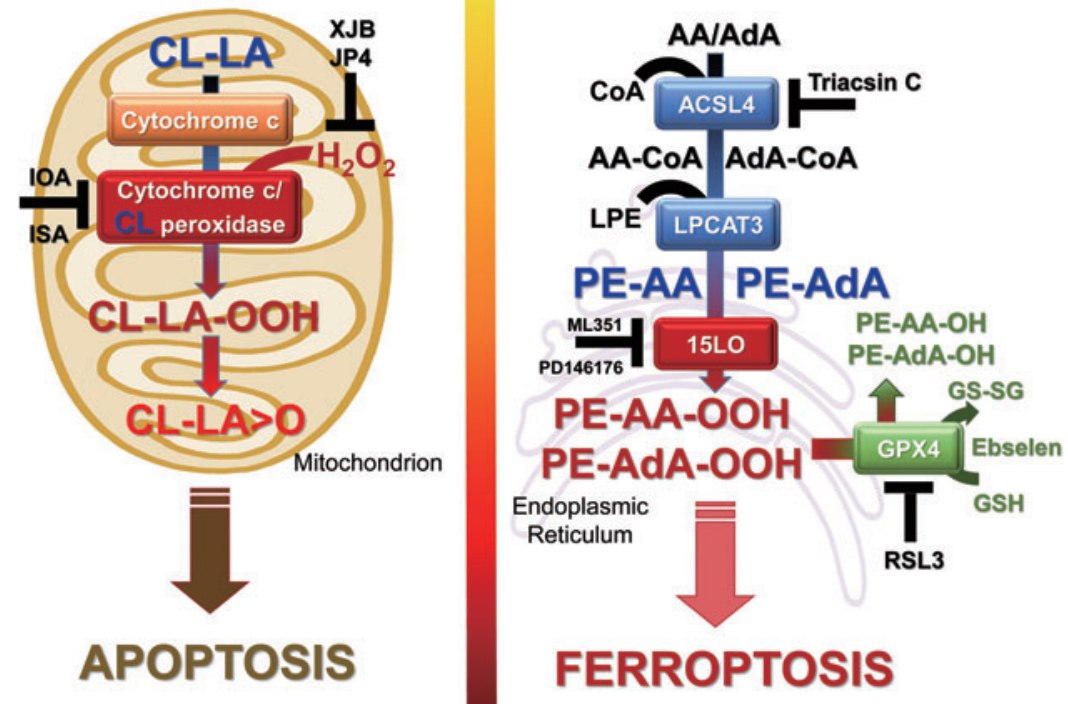

FIG. 5. A schema illustrating the generation of apoptotic and ferroptotic cell death signals from CL (left) and PEs (right). Apoptotic signals, mono-oxygenated species of LA-CL, are formed in mitochondria in the cyt $c / C L-d r i v e n$ reaction. Ferroptotic cell death signals, hydroperoxy-arachidonoyl/adrenoyl PE species (AA-OOH-PE/AdA-OOH-PE) are formed in the endoplasmic reticulum in the 15-LO-driven reaction. Also shown are metabolic pathways involved in the formation of acyl-CoA derivatives of free fatty acids and their subsequent esterification into PE and oxygenation of the phospholipid. The inhibitors of different stages of the process-Triacsin C for ACSL4, ML351 and PD146176 for 15-LO, as well as RSL3 and Ebselen for GPX4-are also presented. GPX4 is central to the regulation of the reduction of AA(AdA)-OOH-PE to the respective hydroxy-derivatives. LA, linoleic acid. To see this illustration in color, the reader is referred to the web version of this article at www.liebertpub.com/ars 


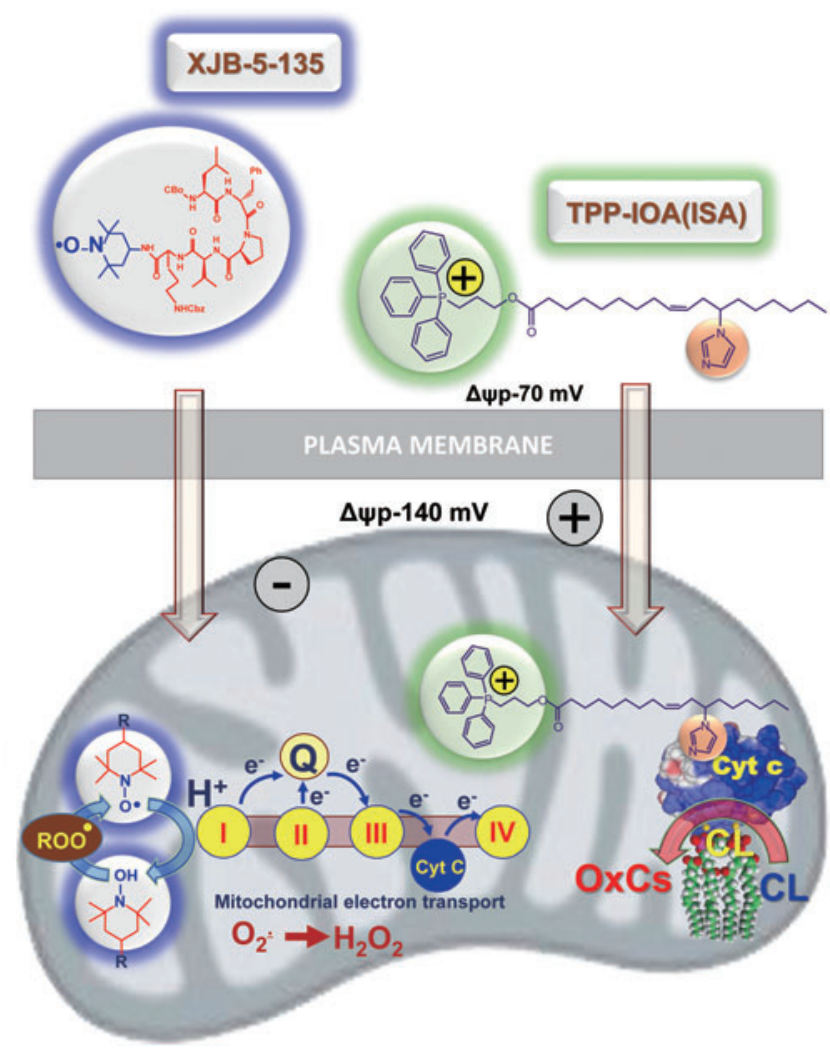

FIG. 6. A schema illustrating protective effects of mitochondria-targeted inhibitors of cyt $c$ driven $C L$ oxidation. The nitroxide group of an electron scavenger, XJB-5-131, prevents the formation of $\mathrm{O}_{2}{ }^{\bullet}$ and $\mathrm{H}_{2} \mathrm{O}_{2}$. The latter is required as a source of oxidizing equivalents for the cyt $c / \mathrm{CL}$ catalyzed $\mathrm{Cl}$ oxidation. Liganding by imidazolesubstituted oleic acid conjugated with a cationic TPP-group (for mitochondrial targeting) of the heme-Fe of cyt $c$ prevents the participation of the enzymatic complex in the catalysis of CL oxidation. To see this illustration in color, the reader is referred to the web version of this article at www.liebertpub.com/ars

residues should be preferred oxidation substrates. Instead, C18:2 residues were found to undergo preferential oxidation within the same CL molecule whereby C20:4 and C22:6 species remained nonoxidized (96).

Similarly, in the lung of animals exposed to hyperoxia, $\gamma$ irradiation, as well as inhaled carbon nanotubes, C18:2 residues were the major targets of oxidation whereas more chemically susceptible polyunsaturated residues displayed lower levels of oxidative modification $(153,156,157)$. Overall, the available results lead to a conclusion that strict control of enzymatic processes rather than stochastic chemical reactions governs apoptosis-associated CL oxidation.

Among the numerous oxidation products, oxygenated CLs with one to eight added oxygen atoms are commonly detectable during LC-MS-based oxidative lipidomics analysis $(65,155)$. Aside from the enzymologic issues related to the mechanisms of cyt $c$ catalyzed reactions, the important question is the relevance of the individual products to the execution of the apoptotic program. Indeed, although only $\sim 10$ molecular species of CLox are found in the brain of normal rats, the elevated levels and more than 150 new ox- ygenated CLox species can be detected after brain trauma (65). Which of these multiple and diversified species of CLox are directly involved in the execution of an apoptotic program? Bioinformatics combined with the newly developed opto-lipidomics approach identified four molecular species of CLox that were persistently associated and common to several cases of apoptosis, when induced in different types of cells and tissues by different stimuli (96). All four of them contained mono-oxygenated C18:2 species, whose structural identity remains to be confirmed. Assuming that the involvement of CLox in the release of cyt $c$ from mitochondria into the cytosol may be mediated by their interactions with one or more proteins in the OMM, one can speculate that electrophilic oxo- or epoxy-derivatives are likely candidates. Further oxidative lipidomics work, particularly based on the application of the new generation of more sensitive high mass accuracy instrumentation (e.g., a Tribrid $^{\mathrm{TM}}$ Fusion $^{\mathrm{TM}} \mathrm{Lu}-$ $\operatorname{mos}^{\mathrm{TM}}$ mass spectrometer; ThermoFisher Scientific), may help in resolving these important questions.

\section{PS Oxidation Signals Phagocytic Clearance of Apoptotic Cells}

Our previous work has shown that execution of an apoptotic program in a variety of cell lines by different intrinsic pro-apoptotic stimuli resulted in selective oxidation of PS in plasma membrane [reviewed in Refs. $(70,71,73)$ ]. Further, we demonstrated that PS oxidation is important for its externalization on the cell surface. We also showed that PS species with docosahexaenoic fatty acid in sn-2 position were oxidized during apoptosis $(152,156)$. Notably, oxygenated PS molecules exposed on the surface of apoptotic cells are better recognized by professional phagocytes, which results in a more effective engulfment and digestion of apoptotic cells. Thus, not only PS $(127,136)$ but also oxidized species of PS act as universal "eat-me" signals (151).

\section{Oxidized PEs Signal Ferroptosis}

The broad regulatory functions of oxygenated polyunsaturated lipids also include involvement in impaired metabolism and disease. In these situations, oxygenated polyunsaturated lipids potentially represent a source of endogenously generated hydrophobic electrophilic carbonyl compounds-aldehydes, ketones, and epoxidescapable of covalently reacting with essential nucleophilic sites in proteins, causing their post-translational modifications that can act as diversified signals or initiators of pathophysiological events $(138,161,163)$. These secondary reactive lipid electrophiles are generated from the common hydroperoxy-precursors, the primary molecular products of lipid peroxidation reactions. Therefore, control of the hydroperoxy-lipids is operated by the key intracellular redox regulatory system-thiols-and their discoordination leads to ferroptosis, a nonapoptotic, iron-dependent form of regulated cell death (43).

Several nonspecific fluorescence-based assays are commonly used to reveal the possible connection of ferroptosis with lipid peroxidation $(40,94)$. Although they all clearly indicate that the process of lipid peroxidation is somehow involved in the execution of ferroptotic program, the real acting products - their identity, structure, and amounts - until recently remained unknown $(29,173)$. Several lipid-related 
A

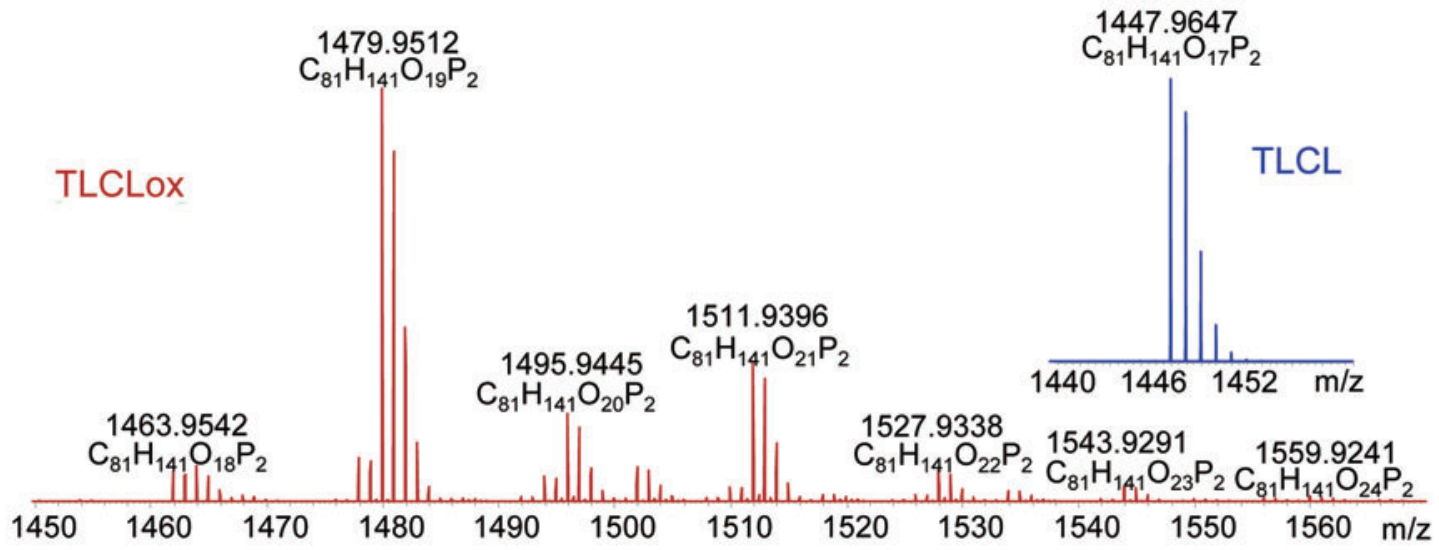

B
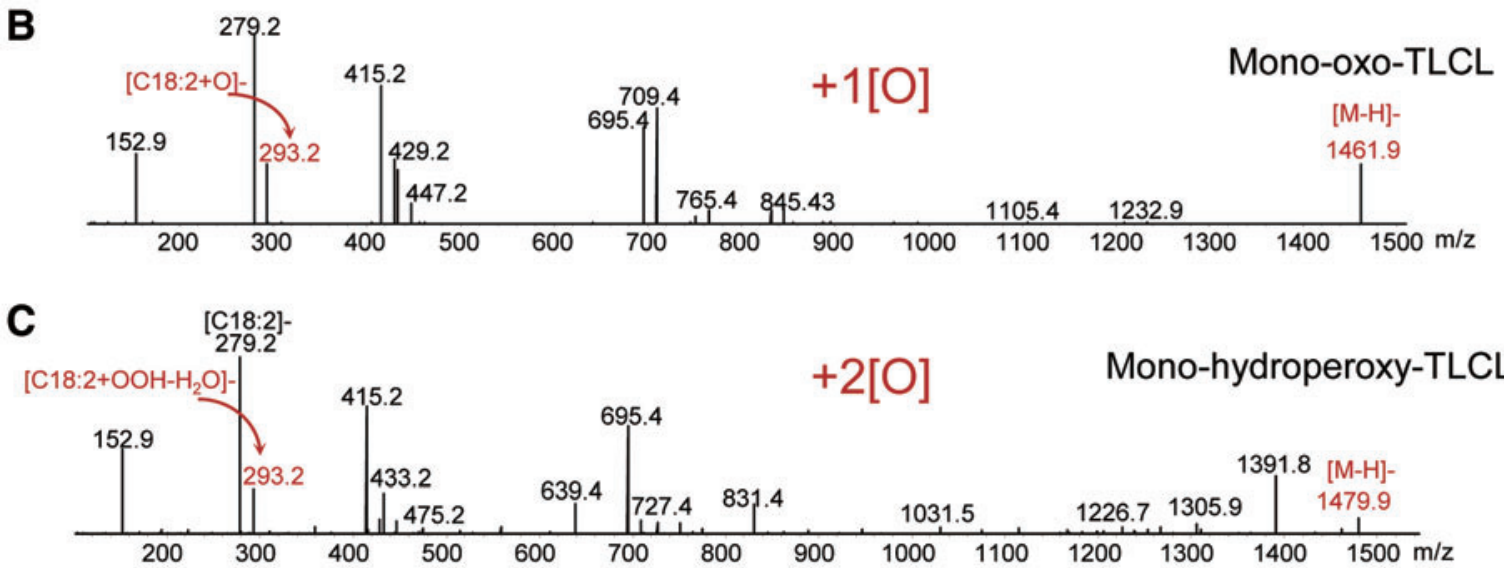

D

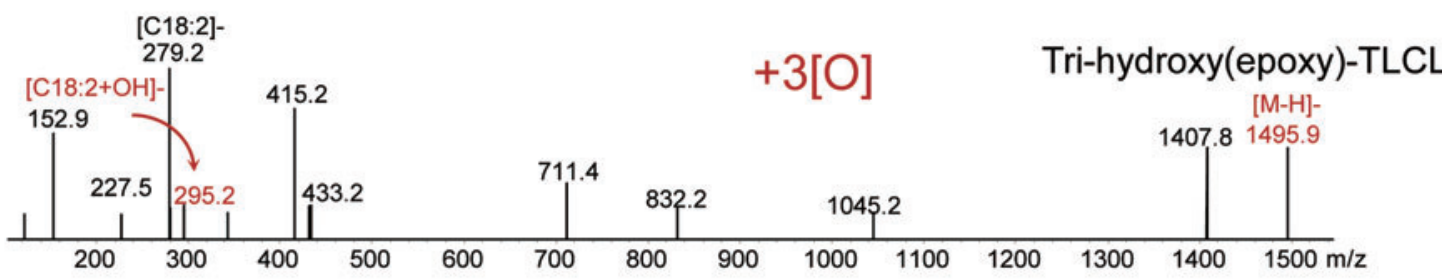

E $\quad[$ C18:2]-
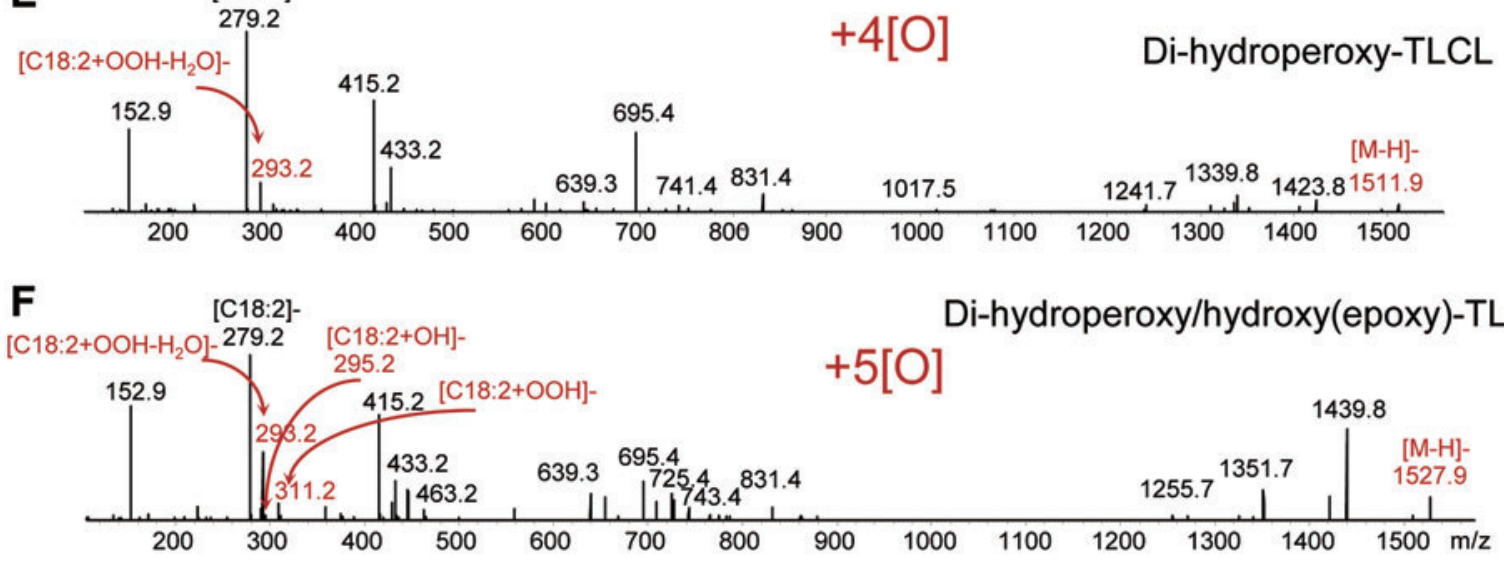

FIG. 7. LC-MS identification of oxygenated TLCL species formed by the peroxidase activity of cyt $c / C L$ complex in the presence of $\mathbf{H}_{2} \mathbf{O}_{2}$. TLCL $(25 \mu M)$ was incubated in the presence of cyt $c(5 \mu M)$ in $25 \mathrm{mM}$ HEPES buffer $\mathrm{pH} 7.4$ containing $100 \mu M$ DTPA. TLCL oxidation products were analyzed by normal-phase LC-MS by using a Q-Exactive mass spectrometer (ThermoFisher Scientific) (155). Shown are full spectra of oxygenated and nonoxygenated (inset) TLCL species (A). MS/MS analysis revealed the presence of TLCL species with one (B), two (C), three (D), four (E), and five (F) oxygens. MS/MS, mass spectrometry; TLCL, tetra-linoleyl-CL. To see this illustration in color, the reader is referred to the web version of this article at www.liebertpub.com/ars 
specific features of ferroptosis have been discovered: (i) deficiency/inactivation of the phospholipid hydroperoxides (PL$\mathrm{OOH}$ ) metabolizing enzyme, GPX4 (40, 173); (ii) sensitivity to iron chelators (29); (iii) rescue by LC-PUFA (arachidonic acid residue) specific acyl-CoA synthase (ACSL4) (30) and lysophospholipid acyl transferase 3 (LPCAT3) $(30,32)$; and (iv) suppression by vitamin $\mathrm{E}$ and other lipophilic antioxidants $(29,40)$. The sensitivity of the ferroptotic outcomes to the earlier mentioned factors has been established on a significant number of different genetically $(30,32)$ and pharmacologically manipulated cancer (29) and normal cell lines (Fig. 8). These facts not only clearly indicate that the process of lipid peroxidation is central and specific to the execution of ferroptosis $(29,172,173)$ but also suggest that representatives of one or more classes of phospholipids are the proximate proferroptotic agents.

Deciphering the nature of the proximate oxygenated lipid signals came from the use of the combination of LC-MSbased global oxidative phospholipidomics with reverse genetics, bioinformatics, and systems biology (75). It was established that only one class of phospholipids, PE, undergoes oxidation in the ER-associated compartments with the specificity toward two fatty acyls - arachidonoyl (AA) and adrenoyl (AdA). Suppression of AA or AdA esterification into PE by knocking out the expression of acyl-CoA synthase 4 (specific for AA) or inhibition of this enzymatic activity by Triacsin $\mathrm{C}$ led to strong protections against ferroptosis, thus confirming that blockade of synthesis of AA-/AdA-PE precursors represented a specific anti-ferroptotic rescue pathway (32).

It was further found that LO, particularly 15-LO, were mostly responsible for the generation of doubly and triply oxygenated PE species, which act as death signals. Notably, the 15-LO-mediated production of oxygenated PE derivatives occurred through attack on the phospholipid molecules rather than on free AA or AdA, with subsequent re-esterification of the hydroperoxy-fatty acids. Creation of GPX4 deficiency achieved through either genetic deletion or chemical inactivation (e.g., by RSL3) or depletion of GSH (e.g., by Erastin) as a source of reducing equivalents $(29,173)$ was absolutely necessary for ferroptosis induction, thus providing further evidence for the primary role of AA-OOH-PE and AdA-OOH-PE in the process (Fig. 5, right panel).

Thus, two metabolic pathways - lipid oxidation by 15-LO and reduction of the oxygenation products by GPX4-are tightly coordinated to generate vitally important oxygenated lipid signals with multiple physiological functions $(64,88$, 135 , 137). Dis-engagement of this system, particularly through the ablation of GPX4, results in the disturbed regulation of the production of electrophilic lipid mediators, thus necessitating the elimination of the impaired cell through the ferroptotic death mechanism.

In line with the complex multistage mechanism of the generation of ferroptotic signals, many small-molecule regulators can be used to control this pathway: (i) LO inhibitors (baicalein, ML351, PD146176), (ii) iron chelators preventing integration of Fe into LO; (iii) regulators of PUFA-PE biosynthesis and remodeling (e.g., inhibitors of ACSL4 like Triacsin C and LPCAT3 like thimerosal) (44); (iv) mimics of glutathione peroxidases, including GPX4 (e.g., Ebselen) (146); and (v) precursors of GSH (like N-acetyl-cysteine, NAC) (4). Interestingly, members of the vitamin E familytocopherols and particularly tocotrienols-turned to be very effective in inhibiting LO as the generator of death signals, thus pointing to a new physiological role of vitamin $\mathrm{E}$ (75). Clearly, each of these regulators can be only effective if it compensates for a specific metabolic pathway deficiency in the biosynthesis of ferroptotic death signals.

Implicit in the name of this type of cell death, ferroptosis is an iron-dependent process. The exact role of iron, however, in the overall chain of reactions is still unclear. Although LO enzymes are involved in the generation of essential lipid peroxidation-derived death signals, it is conceivable that they

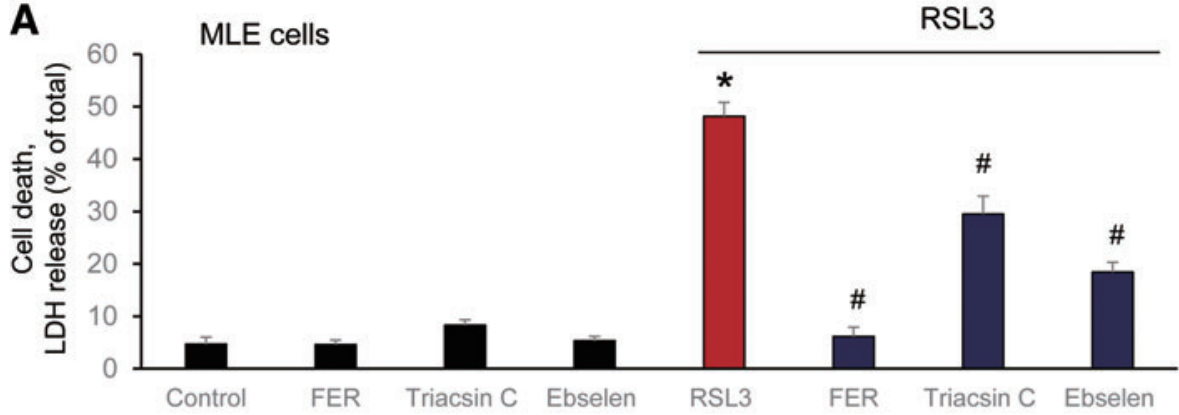

B

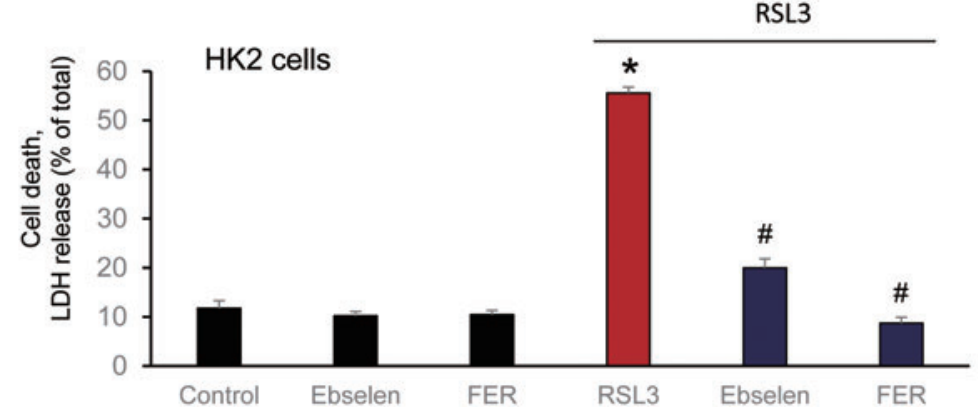

FIG. 8. Effect of different ferroptosis inhibitors-ferrostatin (FER), ebselen (a GPX mimic), and triacsin C (Acls4 inhibitor)on RSL3-induced ferroptosis in MLE (A) and (B) HK2 cells. MLE cells: (RSL3: $1 \mu M$, Ebselen: $5 \mu M$; FER: $0.1 \mu M$ and triascin $\mathrm{C}: 5 \mu M$ ). HK2 cells: (RSL3: $200 \mathrm{n} M$, Ebselen: $4 \mu M$, and FER: $0.2 \mu M$ ). ${ }^{*} p<0.05$ versus control. ${ }^{\#} p<0.05$ versus RSL3. Data are mean \pm SD., $n=3$. HK2, human kidney epithelial; MLE, mouse lung epithelial; $\mathrm{SD}$, standard deviation. To see this illustration in color, the reader is referred to the web version of this article at www.liebertpub.com/ars 
are not unique as either enzymatic or nonenzymatic mechanisms that can trigger ferroptosis $(31,40,75,172,176)$. There is a common opinion-although poorly substantiated by experimental data-that free iron (that can be scavenged by high-affinity chelators) may be mostly responsible for the pro-ferroptotic lipid peroxidation (176). It is also presumed that Fenton/Haber-Weiss chemistry $(84,175)$ leading to hydroxyl radical formation-rather than strictly regulated enzymatic peroxidation-is mostly accountable for the generation and emanation of hydroperoxy-lipids. Although the participation of nonenzymatic mechanisms in the production of these products cannot be fully excluded, the stochastic nature of these chemical reactions makes it very unlikely and essentially incompatible with the high specificity of the major pro-ferroptotic signals-15-hydroperoxy-AA/AdA$\mathrm{PE}$. Based on the partial identification of the pro-ferroptotic signals such as 15-hydroperoxy-AA-PE (15-HpETE-PE), it is likely that 15 -LO, including both of its isoforms-15-LO1 and 15-LO2 (75) - define the specificity of lipid-driven death pathways in different tissues. It is also possible that other Fe-containing proteins, including hemoproteins and other representatives of the $\mathrm{LO}$ family, may act as important contributors
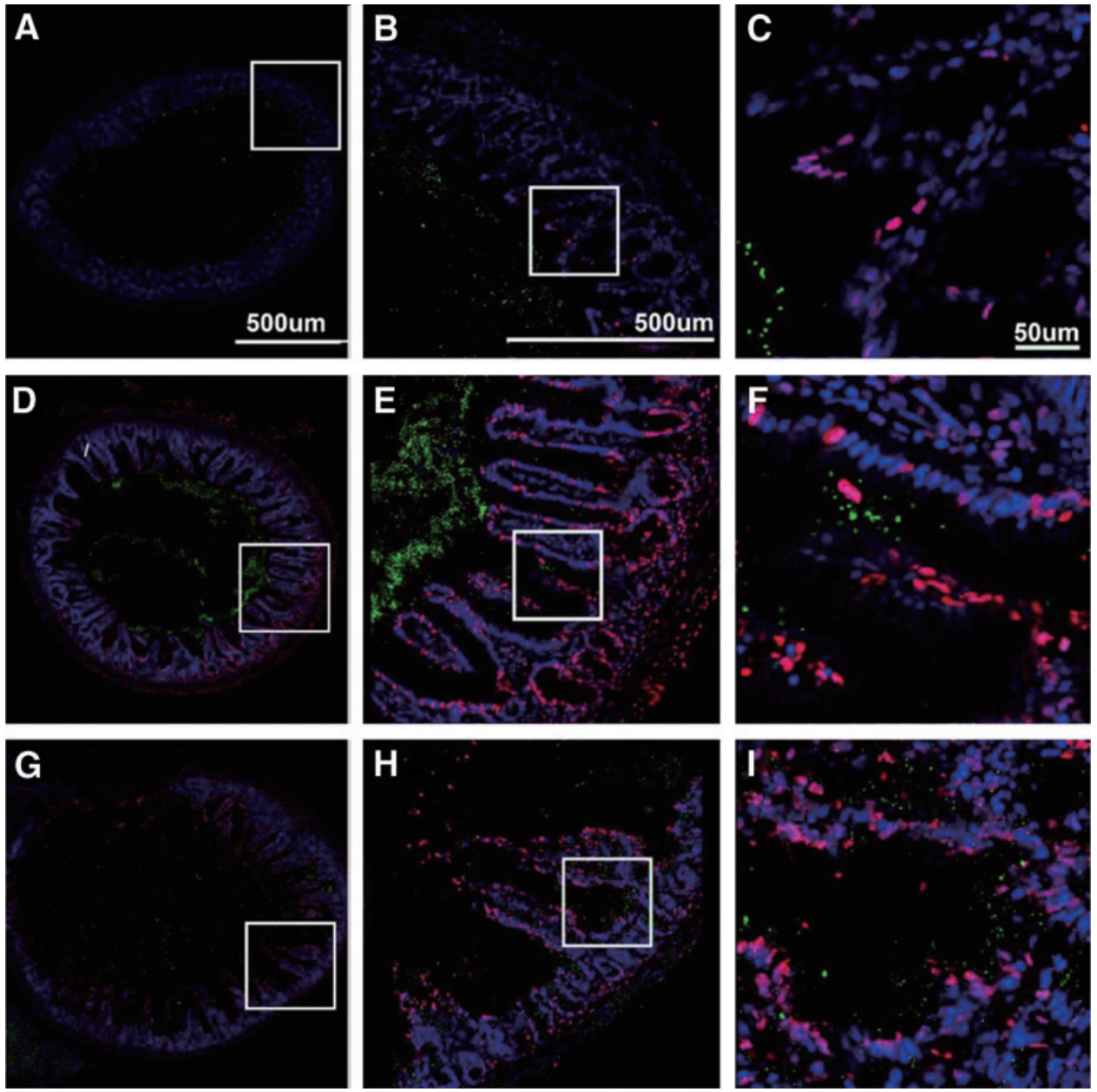

FIG. 9. Radiation-induced injury of the ileum 1, 3, and 5 days after TBI of mice. C57BL/6NTac adult female mice were irradiated to the $\mathrm{LD}_{50 / 30}$ dose of $9.25 \mathrm{~Gy}$ TBI, and $12 \mathrm{~h}$ before sacrifice lavaged with $200 \mathrm{~nm}$ fluorescent beads ( $\mathrm{green}$ ). All procedures were preapproved and performed according to the protocols established by the Institutional Animal Care and Use Committee of the University of Pittsburgh. Samples were fixed, sectioned, and stained to show cellular apoptosis. (A), (D), and (G) are low power large area montages of entire bowel sections; $(\mathbf{B}),(\mathbf{E})$, and $(\mathbf{H})$ are the inset panels from $(\mathbf{A})$, $(\mathbf{D})$, and $(\mathbf{G}) ;(\mathbf{C}),(\mathbf{F})$, and $(\mathbf{I})$ are the insets from $(\mathbf{B}),(\mathbf{E})$, and $(\mathbf{H})$. In control animals (not shown), apoptosis is very rare and limited to epithelia in the villus apex. As can be seen from these image sequences, there is a clear and quantitative increase in the number of apoptotic cells (red) with time after irradiation. In addition, there is a coincident and concomitant increase in the number of particles escaping the luminal space into the adventitia and beyond. In (A) (1 day after irradiation), it can be seen that apoptosis is rare, limited to the epithelium (B) and primarily to the apex of the villus (C). Green particles do not escape the lumen of the ileum. In (D) (3 days after irradiation), it can be seen that although there is some increase in apical apoptosis, it is now continuous throughout the length of the villus, and also present within the cells of the serosa and adventitia (E). Further, as there is some collapse of villi, there is escape of beads from the lumen into the serosa (F). In (G) (5 days after irradiation), apoptosis is ubiquitous and villi structure is largely lost. Further, there is extensive penetration of beads into the serosa and adventitia as the ileum wall is compromised. All vertical columns are at the same magnification and defined in panels (A-C). TBI, total body irradiation. To see this illustration in color, the reader is referred to the web version of this article at www.liebertpub.com/ars 
to tissue-specific mechanisms of ferroptosis. Therefore, it is interesting to consider the relationships of LO-generated products released from different types of diverse cell types as regulators of several oxygenated lipid mediators in the context of their possible putative involvement in ferroptosis in vivo.

\section{Signaling by Free and Esterified Oxygenated Lipids in Acute Radiation Injury as an Inflammatory Disease: Sequential Engagement of Different Programmed Cell Death Pathways}

TBI causes radiolysis of water-the most abundant component of our body in cells, extracellular compartments, and biological fluids (57). The reactive intermediates of this process_-reducing and oxidizing radicals_randomly attack different components of cells although with different biological consequences largely defined by the uniqueness of modified molecules (89). Although aqueous radicals can directly interact with proteins, lipids, and carbohydrates, these reactions do not represent totally irreparable events and may be effectively repaired through standard catabolic and metabolic processes. In contrast, accumulation of single- and double-strand breaks in DNA beyond the capacity of the repair systems generates “danger" signals $(117,118)$. These danger signals produced in hematopoetic cells of bone marrow and epithelial cells of the small intestine-occurring early after the radiation exposure-trigger the mitochondrial mechanisms of intrinsic apoptosis, thus leading to elimination of cells-carriers of genotoxic materials $(117,118)$.
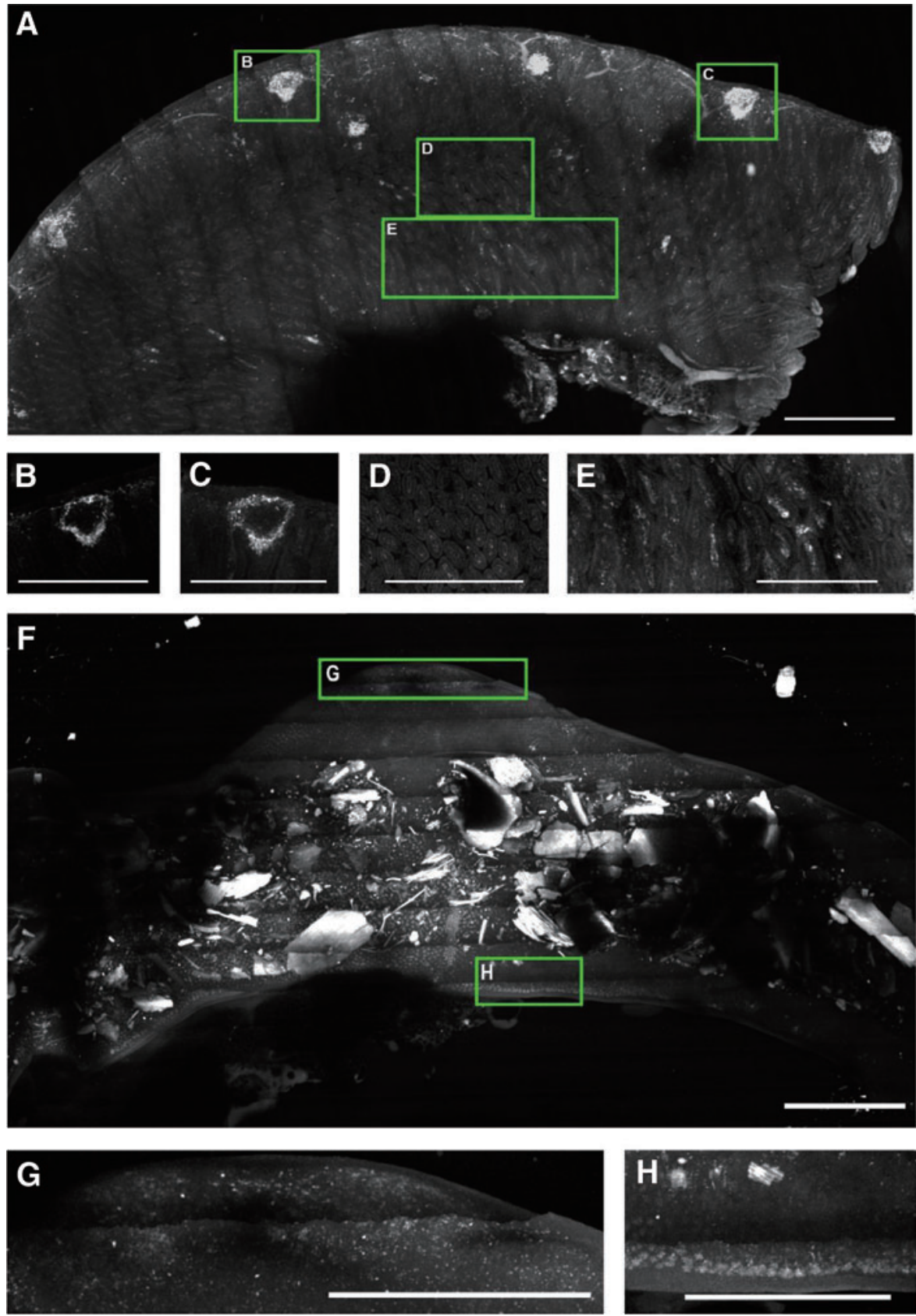

FIG. 10. Large volume scanning of mouse ileum 1 and 7 days after TBI. Mice expressing GFP within neutrophils were irradiated $(9.25 \mathrm{~Gy})$ and sacrificed at 1 and 7 days after irradiation. The ileum was harvested, fixed in $4 \%$ paraformaldehyde, and placed in clearing solution (CUBIC1) for a week. The samples were then mounted in a prototype high-speed ribbon scanning system, and the entire ileum volumes were captured. (A) is a three-dimensional projection of the entire thickness of the ileum 1 day after irradiation. There is a small amount of autofluorescence from the blood vessels. Peyer's patches [e.g., insets denoted $(\mathbf{B}, \mathbf{C})]$ have abundant neutrophils associated with the patch. When the same patches are imaged as optical sections, it can be seen that cells are limited to the periphery of the structure $(\mathbf{B}, \mathbf{C})$. Further, it can be seen that villus structure (in common with A) is well maintained [in cross-section in (D) and longitudinal section (E)]; however, there are abundant bright spots (denoting neutrophils) within these structures. (F) is an equivalent sample to (A), the autofluorescent material within the lumen is murine chow. The notable features of the sample are the progression from healthy tissue to a complete absence of structure. Neutrophils are still present (G); however, the villi, serosa, and most of the adventitia are lost from the tissue. At this point, the ileum is extremely fragile and about to fail completely (H). Scale bars: $1 \mathrm{~mm}$. To see this illustration in color, the reader is referred to the web version of this article at www.liebertpub .com/ars 

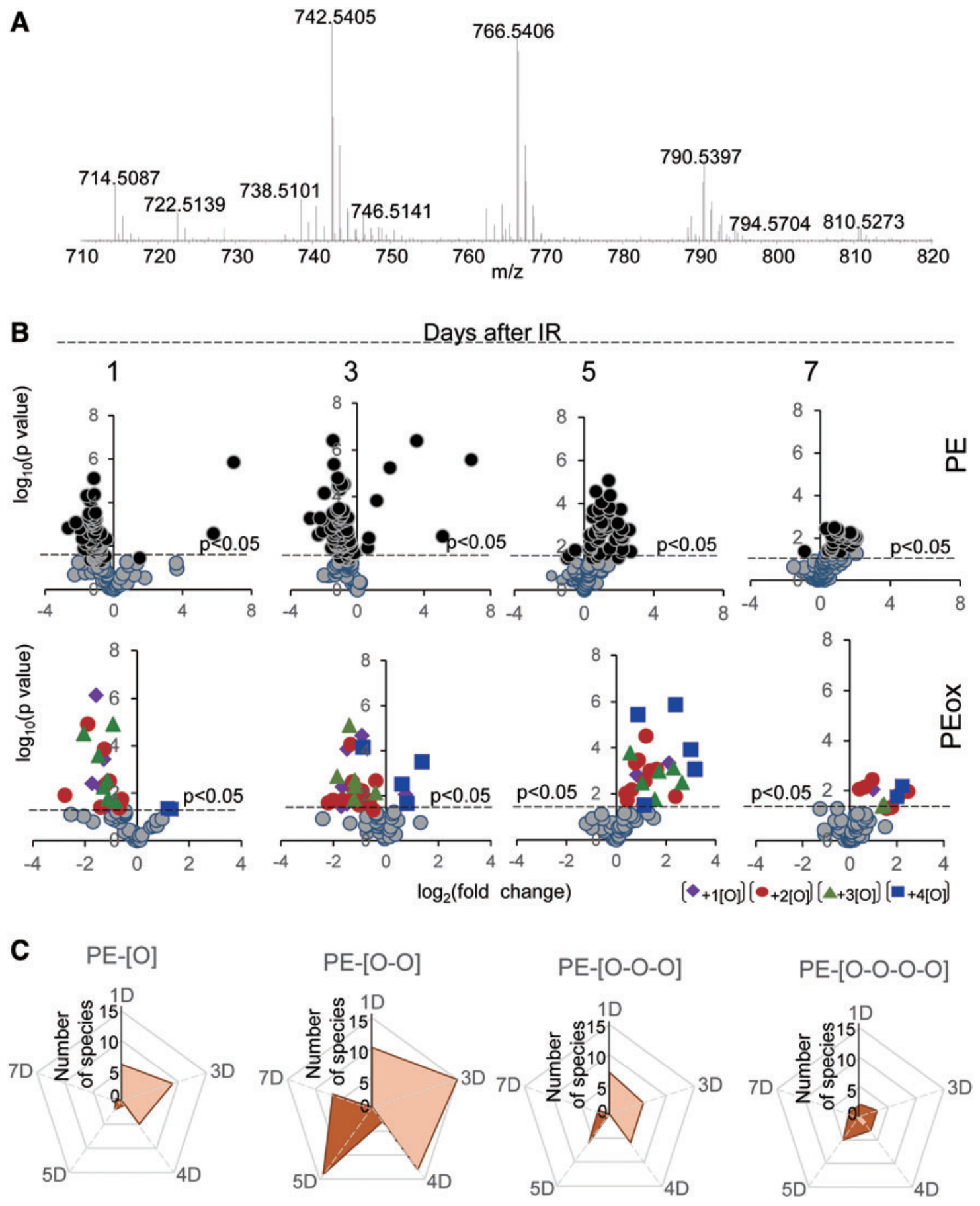

diminished

accumulated

FIG. 11. Analysis of PE molecular species in the ileum of mice exposed to TBI. C57BL/6NTac mice were exposed to TBI at a dose of $9.5 \mathrm{~Gy}$. After that, mice were sacrificed, ileum was isolated, lipids were extracted, and detailed normalphase LC-MS/MS analysis of PE molecular species was performed (75). Analysis of nonoxidized PE metabolites revealed 115 molecular species of PE, 58 of which were confirmed by fragmentation and MS/MS analysis (Table 1). Analysis of LCMS data was performed by using software package Compound Discoverer ${ }^{\mathrm{TM}}$ (ThermoFisher Scientific). Typical full spectrum of PE obtained from the mouse ileum (A). Scatter plot of changes in the levels of nonoxygenated (upper panels) and oxygenated (lower panels) PE species ( $\log _{2}$ [fold-change] vs. significance $-\log _{10}[p$-value] $[n=4])(\mathbf{B})$. The number of PE oxygenated species detected in mouse ileum after TBI are shown in (C). PE, phosphatidylethanolamine. To see this illustration in color, the reader is referred to the web version of this article at www.liebertpub.com/ars 
These initial events - although happening on a relatively small scale-are remarkably important. This is because the elimination of the primary sensitive cells directly injured by radiation awakens very strong responses of the innate immune system whose capacity to kill the neighboring cells within the microenvironment exceeds the chemical modifying potency of the initial radiation-induced intermediates of water radiolysis. Massive production of potent oxidants by activated neutrophils (predominantly hypochlorous acid) and macrophages (mostly peroxynitrite and hydroxyl radicals) causes substantial collateral damage by injurious modification of innocent by-stander cells. Engagement of these secondary target cells magnifies the innate immune response and, hence, propagates the initial direct radiation effect, thus initiating a vicious cycle of massive and delayed cell death $(90,103)$. Notably, the secondary death pathways are not limited to apoptosis but include other types of programmed death, such as necroptosis and ferroptosis (61).

Another enhancing cascade, breach of the intestinal epithelial barrier, designates the transition from "sterile" to infectious inflammation, ultimately leading to sepsis and multiple organ failure and thus worsening the overall prognosis and decreasing survival $(46,48)$. In spite of the calamitous nature of radiation inflammatory disease, its sequential development with characteristic phases and dominating cell death pathways gives an encouraging promise for multiple therapeutic approaches within the newly developed concept of precision medicine-accurately timed application of specific regulators targeting selective pathogenic mechanisms and pathways. Of course, the application of the principles of precision medicine necessitates the profound understanding of the mechanisms involved, particularly specific signals regulating recruitment, activation, and guidance of inflammatory cells to maximize their effectiveness in eliminating radiation-induced damage with minimal effects of "friendly fire" (170).

Among the major regulators of immune responses are different eicosanoids and docosanoids, as well as cytokines $(14,26$, $27,67,171)$. Although experimental and clinical applications of cytokine analysis have been substantially improved over the

Table 1. Phosphatidylethanolamine Molecular Species of Mouse Ileum

\begin{tabular}{|c|c|c|c|}
\hline$m / z$ & $D i-a c y l-P E$ & Alkyl-PE & Alkenyl-PE \\
\hline 714.5079 & $16: 0 / 18: 2$ & & \\
\hline 716.5236 & $16: 0 / 18: 1$ & & \\
\hline 722.5130 & & & p16:0/20:4 \\
\hline 724.5287 & & o16:0/20:4 & \\
\hline 726.5443 & & & p18:0/18:2 \\
\hline 728.5600 & & o18:0/18:2; o18:1/18:1 & \\
\hline 730.5756 & & o18:0/18:1 & \\
\hline 736.4923 & $16: 1 / 20: 4$ & & \\
\hline 738.5079 & $18: 2 / 18: 2 ; 16: 0 / 20: 4$ & & \\
\hline 742.5392 & $18: 0 / 18: 2$ & & \\
\hline 744.5549 & 18:0/18:1 & & \\
\hline 746.5705 & $18: 0 / 18: 0$ & & \\
\hline 746.5130 & & o16:1/22:6 & p16:0/22:6 \\
\hline 750.5443 & & o18:0/20:5; o16:0/22:5 & p18:0/20:4 \\
\hline 752.5600 & & o18:0/20:4; o16:0/22:4 & \\
\hline 756.5913 & & o18:0/20:2 & \\
\hline 762.5079 & $18: 2 / 20: 4 ; 18: 1 / 20: 5 ; 16: 0 / 22: 6$ & & \\
\hline 764.5236 & $18: 1 / 20: 4 ; 18: 0 / 20: 5 ; 16: 0 / 22: 5$ & & \\
\hline 766.5392 & $18: 0 / 20: 4 ; 16: 0 / 22: 4$ & & \\
\hline 768.5549 & $20: 1 / 18: 2 ; 18: 0 / 20: 3$ & & \\
\hline 774.5443 & & & p18:0/22:6 \\
\hline 776.5600 & & o18:0/22:6 & p18:0/22:5 \\
\hline 778.5756 & & & p20:0/20:4; p18:0/22:4 \\
\hline 780.5913 & & o20:0/20:4; o18:0/22:4 & \\
\hline 784.6226 & & o18:0/22:2 & \\
\hline 786.5079 & $20: 4 / 20: 4 ; 18: 2 / 22: 6$ & & \\
\hline 790.5392 & $20: 2 / 20: 4 ; 18: 0 / 22: 6$ & & \\
\hline 792.5549 & $20: 1 / 20: 4 ; 18: 0 / 22: 5$ & & \\
\hline 798.6018 & $22: 0 / 18: 2$ & & \\
\hline 802.5756 & & & p20:0/22:6 \\
\hline 804.5913 & & o20:0/22:6 & \\
\hline 806.6069 & & & p20:0/22:4; p18:0/24:4 \\
\hline 808.6226 & & o18:0/24:4 & \\
\hline 820.5862 & $22: 1 / 20: 4 ; 20: 1 / 22: 4$ & & \\
\hline 822.6018 & $22: 0 / 20: 4$ & & \\
\hline 846.6018 & $24: 2 / 20: 4$ & & \\
\hline 848.6175 & $24: 1 / 20: 4$ & & \\
\hline 850.6331 & $24: 0 / 20: 4$ & & \\
\hline
\end{tabular}

PE, phosphatidylethanolamine. 
past decade, the complexity of eiocosanoid and docosanoid signaling systems is much greater and lacks the necessary level of understanding. This particularly relates to esterification/deesterification processes that may act via entirely different mechanisms and receptor systems $(3,83)$.

LC-MS analysis can provide unique information on the production of the most essential lipid mediators in free and esterified forms. This relates to the eicosanoids leukotriene $\mathrm{B}_{4}\left(\mathrm{LTB}_{4}\right)$ and hepoxilin $\mathrm{A}_{3}\left(\mathrm{HXA}_{3}\right)$ - the major regulators of neutrophil recruitment and penetration through the epithelium/mucosal layers when encountering bacterial pathogens $(104,106)$.

To illustrate some of the new opportunities offered by the LC-MS-based oxidative lipidomics in linking the prototypical radiation-induced responses with the production of esterified and nonesterified oxygenated lipid signals, we will consider the effects of a lethal dose of TBI (9.5 Gy) on damage to the ileum. The initial massive epithelial apoptosis is followed by the accumulation of activated neutrophils, where their dysregulated migration through the epithelium and "discharge" of reactive oxidizing intermediates leads to disintegration and breach of the epithelial barrier (Figs. 9 and 10). Phospholipidomic assessments of nonoxidized PE metabolites revealed 115 molecular species of PE based on accurate mass analysis (Fig. 11 and Table 1). In the ileum, high levels of oxidizable PUFA acyls-linoleic (C18:2), arachidonic (C20:4), eicosapentaenoic (C20:5), adrenic (C22:4), docosapentaenoic (C22:5), and docosahexaenoic (C22:6) are esterified into diversified PE species (Table 1). Accordingly, MS/MS analysis identified di-oxygenated signals of PE with $\mathrm{HXA}_{3}$ esterified into sn-2 position (PEp16:0/HXA 3 ; PEp18:0/HXA 3 ) (Fig. 12A). Early after TBI (day 1), a significant decrease of doubly-oxygenated PE species (Fig. 12B) was accompanied by the accumulation of both lyso-PE (LPE) (Fig. 13A) and free $\mathrm{HXA}_{3}$ (Fig. 13B). This suggests the involvement of 12-LO in the radiation-induced responses whereby a direct attack on AA-PE substrate and oxygenation of the phospholipid is likely followed by hydrolysis of the oxygenated product to yield free $\mathrm{HXA}_{3}$ and lyso-PE. Further, a fourfold accumulation of $\mathrm{LTB}_{4}$ - an eicosanoid that is synthetized by 5 -LO in neutrophils and is involved in inflammatory response-was also observed (Fig. 13C).

Radiation-induced lipid oxygenation responses were also accompanied by typical changes in the levels of cytokines and chemokines participating in the recruitment and regulation of neutrophils (Fig. 13D). Thus, radiation-triggered responses include a series of sequential reactions associated with the recruitment and guidance of neutrophils to and within the inflammation site (Fig. 9). The detailed characterization of PE oxidation products as potential sources of important lipid mediators-along with the detailed time course of cytokine formation-may be important for the development of mechanism-based targeted and "personalized" therapeutic approaches.

Concomitantly with these processes of phospholipid oxygenation and hydrolysis - leading to the release of "free" signaling lipid mediators-accumulation of esterified oxygenated phospholipids associated with different types of programmed cell death occurred. Cyt $c$ catalyzed oxidation of $\mathrm{CL}$ and 15-LO catalyzed oxidation of AA-PE were also triggered, resulting in the production of pro-apoptotic and pro-ferroptotic signals, respectively $(156,157)$ (Fig. 14). Fragmentation patterns of PE species from the ileum showed that 18 molecular species contained arachidonic acid (20:4) potential precursors of ferroptotic death signals. Robustly increased levels of PEox were detected at 5 days postirradiation (Fig. 14). Overall, 27 oxygenated PEs were revealed by oxidative phosholipidomics, of which doubly oxygenated PEs represented the most abundant derivatives, in terms of both the number of species (Fig. 11) and their contents (Fig. 14A). Structural analysis revealed 14 doubly oxygenated species of PE versus 2 mono-, 6 tri-, and 5 four- oxygenated
FIG. 12. Identification of $\mathrm{HXA}_{3}$ esterified into $\mathrm{PE}$ in the ileum of mice after TBI. MS/MS spectrum of PE molecular species with $\mathrm{m} / \mathrm{z}$ 754.58 (A) and structural formulas of $\mathrm{HXA}_{3}-\mathrm{PE}$ species (A, insets). $\mathrm{HXA}_{3}-\mathrm{PE}$ species originated from PEp16:0/20:4 and PEp18:0/ 20:4 after the addition of two oxygens. The level of $\mathrm{HXA}_{3}$ $\mathrm{PE}$ in the ileum of naive mice and mice exposed to TBI $(9.5$ Gy) (B). The data on the contents of esterified PE in the ileum of irradiated mice were obtained by detailed LC-MS/MS analysis (75). Data are mean $\pm \mathrm{SD}, n=4$. To see this illustration in color, the reader is referred to the web version of this article at www.liebertpub.com/ars
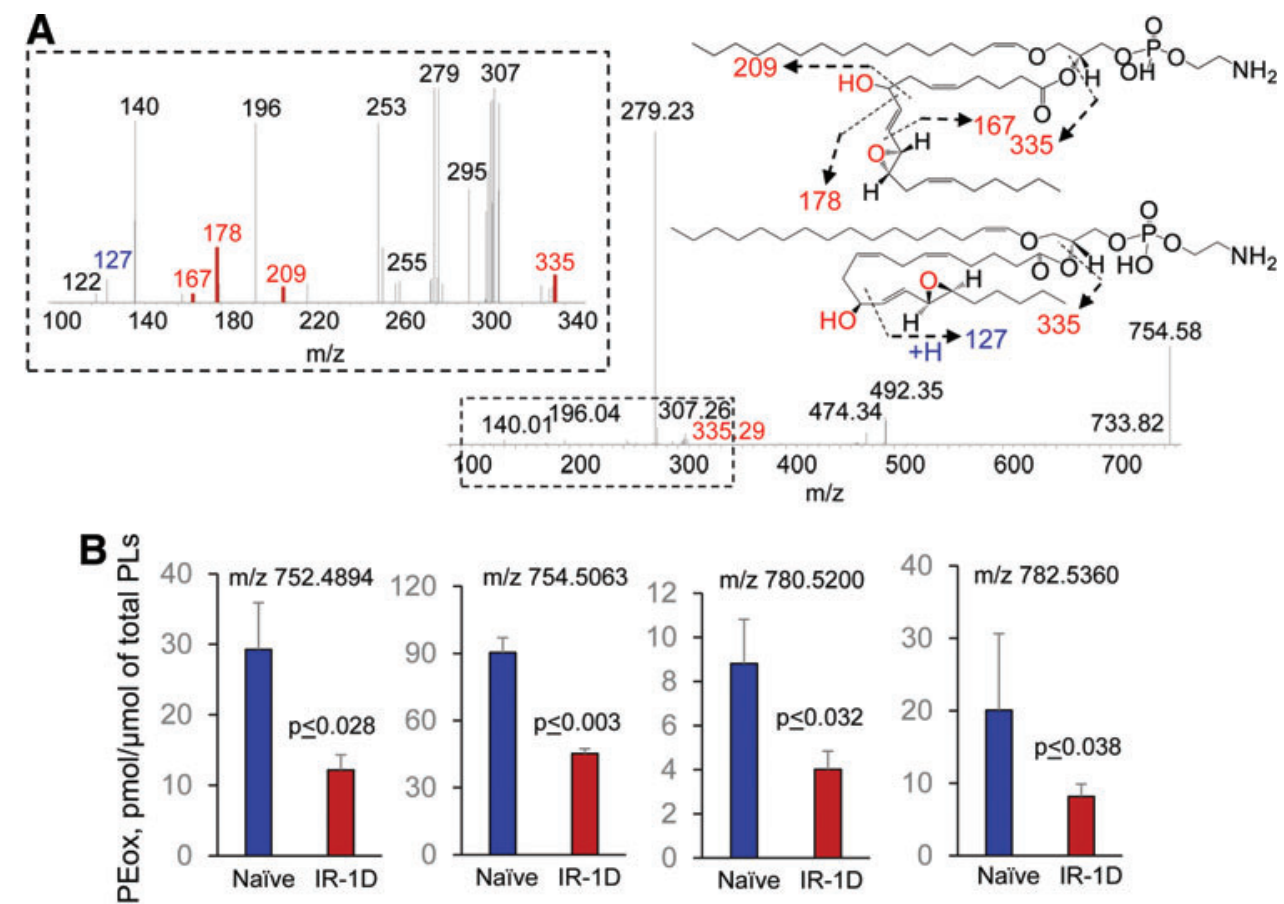

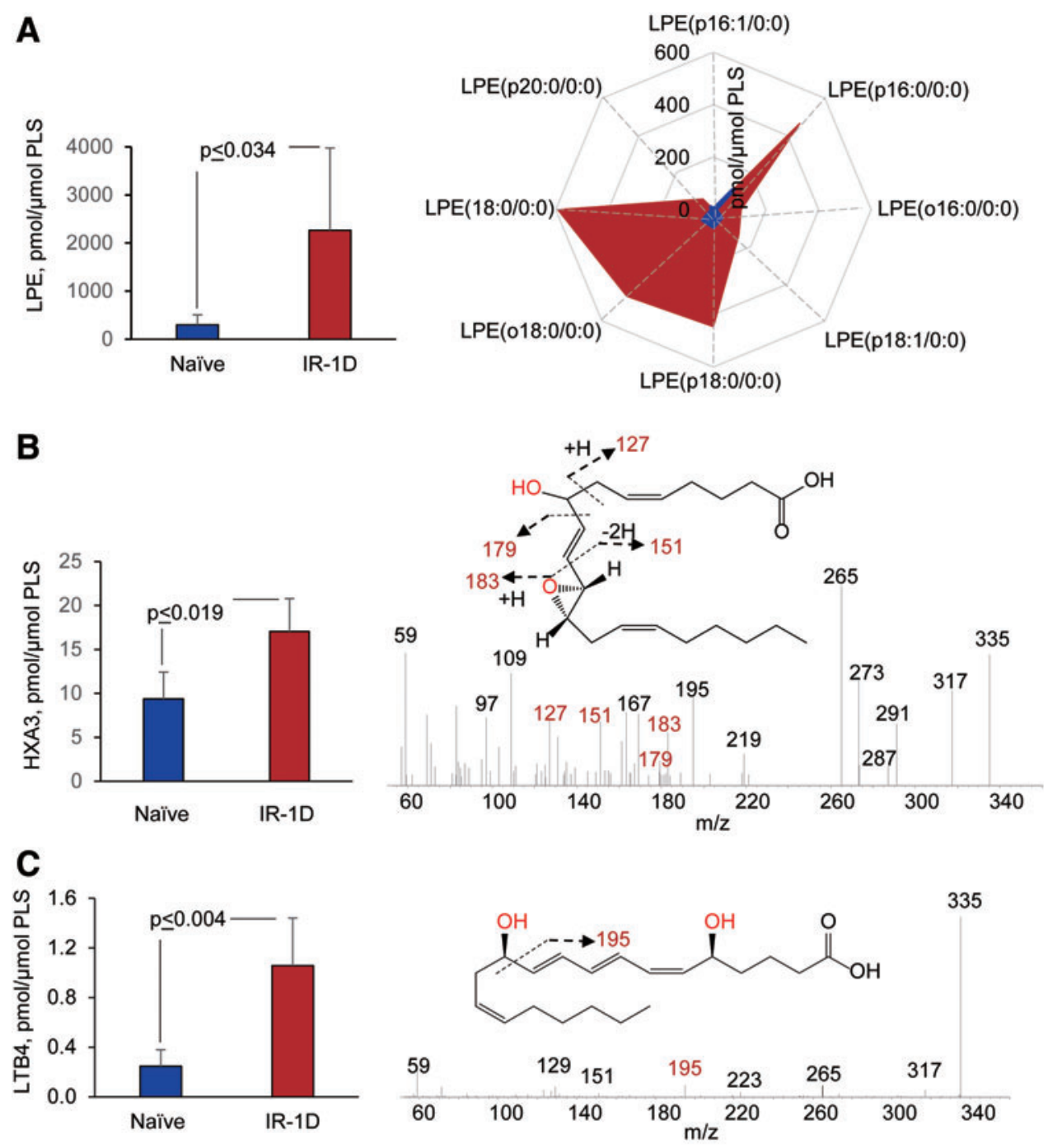

\begin{tabular}{|r|c|c|c|c|c|c|c|c|}
\hline & 0 Day & 1 Day & 2 Days & 3 Days & 4 Days & 5 Days & 6 Days & 7 Days \\
\hline MCP-1 & 13.6 & 21.7 & 56.0 & 27.3 & 16.2 & 18.9 & 38.3 & 16.7 \\
\hline KC & 9.7 & 9.0 & 9.2 & 7.3 & 9.3 & 27.5 & 33.7 & 22.2 \\
\hline RANTES & 13.7 & 7.4 & 58.7 & 41.3 & 20.5 & 11.1 & 15.5 & 1.7 \\
\hline \multicolumn{1}{|c}{$\mathrm{pg} / \mathrm{mg}$ protein } & 60
\end{tabular}

FIG. 13. Accumulation of PEox hydrolysis products and lipid mediators in the ileum of mice exposed to TBI (9.5 Gy). LPE species and oxygenated free fatty acids were analyzed by normal-phase and reverse-phase LC-MS, respectively, by using a Q-Exactive mass spectrometer (ThermoFisher Scientific). Accumulation of total LPE (A, left panel) and LPE molecular species (A, right panel) in the ileum of naïve mice (blue) and irradiated mice (1 day after irradiation, red). Data are mean $\pm \mathrm{SD}, n=4$. The content of free $\mathrm{HXA}_{3}$ in the ileum of naive mice (blue) and irradiated mice (1 day after irradiation, red), (B, left panel). Data are mean $\pm \mathrm{SD}, n=4$. MS/MS spectrum of molecular ion with $\mathrm{m} / \mathrm{z} 334.22$ at $\mathrm{HXA}_{3}$ retention time (B, right panel). Characteristic $\mathrm{HXA}_{3}$ fragments formed during MS/MS analysis (m/z 127, m/z 151, m/z 179 and m/z 183) are shown in red. Accumulation of free $\mathrm{HXA}_{3}$ in the ileum of irradiated mice might be due to hydrolysis of $\mathrm{PE}-\mathrm{HXA}_{3}$ species by phospholipase $\mathrm{A}_{2}$ and liberation $\mathrm{HXA}_{3}$ from the sn-2 position of PE. Notably, the LPE species originated from alkenyl and alkyl PE species. The content of free $\mathrm{LTB}_{4}$ in the ileum of naive mice (blue) and irradiated mice (1 day after irradiation, red). Data are mean $\pm \mathrm{SD}, n=5$ (C, left panel). MS/MS spectrum of the molecular ion with $\mathrm{m} / \mathrm{z} 334.22$ at $\mathrm{LTB}_{4}$ retention time (C, right panel). Characteristic $\mathrm{LTB}_{4}$ fragment formed during MS/MS analysis (m/z 195) is shown in red. Cytokine production in the ileum of irradiated mice (D). Cytokine production was by Luminex immunoassays run on the intestine for each group ( $n=4-5$ each data point) at serial time points at days 0 (before irradiation), 1, 2, 3, 4, 5, 6, or 7 after TBI. Shown are "heat maps" for three proteins (RANTES that plays an important role in the recruitment of neutrophils to the inflammatory sites), KC (a homolog of a neutrophil recruiting human pro-inflammatory cytokine, IL-8) along with MCP1 (a monocyte chemoattractant protein 1). LPE, lyso-phosphatidylethanolamine species; $\mathrm{LTB}_{4}$, leukotriene $\mathrm{B}_{4}$. To see this illustration in color, the reader is referred to the web version of this article at www.liebertpub.com/ars 
FIG. 14. Accumulation of PE oxygenated species in the ileum of mice exposed to TBI (9.5 Gy). The contents of mono-, di-, tri-, and tetra-oxygenated PE species in the ileum of naive mice and mice exposed to TBI (A). The ileum lipids were analyzed by normal-phase LC-MS by using a Q-Exactive mass spectrometer using software package Compound Discoverer (ThermoFisher Scientific) with an in-house generated analysis workflow and oxidized phospholipid database. Data are mean $\pm \mathrm{SD}, n=5$, ${ }^{*} p<0.05$ versus naive (0 day) nonirradiated mice. Note: The elevated levels of oxygenated PE species in the ileum were detected on days 4-7 after exposure irradiation. The significant level of PE-18:0/20:4-OOH, a ferroptotic cell death signal, was detected in the ileum on day 5 after irradiation (B). Data are mean $\pm S D$, $n=5$. To see this illustration in color, the reader is referred to the web version of this article at www .liebertpub.com/ars
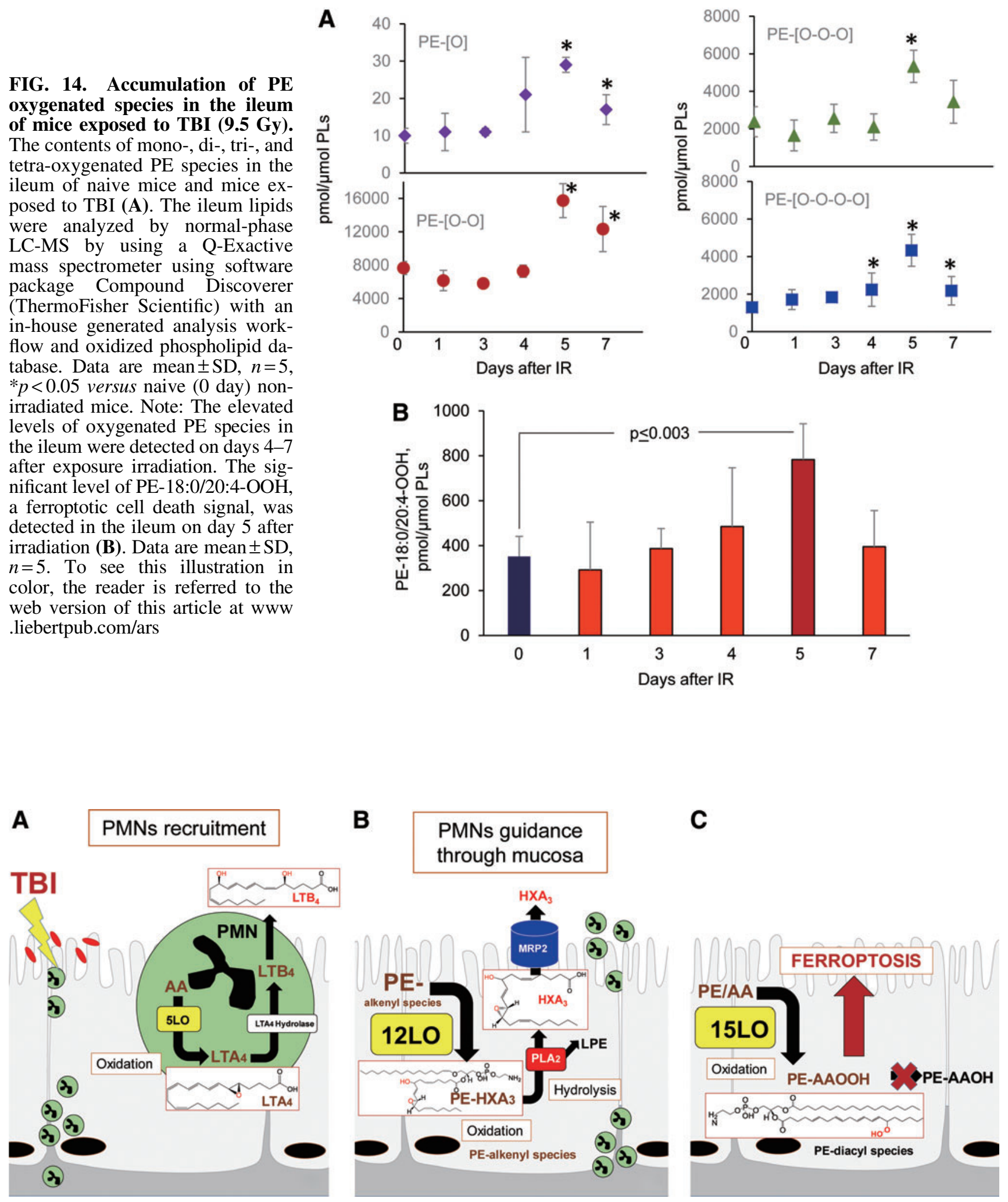

C

FIG. 15. A schema illustrating the TBI-induced signaling pathways as well as the formation and metabolic conversions of lipid mediators and their targets in the intestinal epithelium. (A) Production of chemotactic lipid mediator, LTB4, and its appearance in the circulation is essential for the recruitment of polymorphonuclear leukocytes (PMNs) to the site of damage. (B) Intestinal epithelial cells generate free and esterified forms of $\mathrm{HXA}_{3}$. MRP2 that is highly expressed at the apical surface of the intestinal epithelia pumps out free $\mathrm{HXA}_{3}$ that acts as a signal for neutrophils guiding their movements through the mucosal layer (1). (C) Finally, the formation of AA-OOH-PE triggers ferroptotic death of epithelial cells. MRP2, multidrug resistance-associated protein 2. To see this illustration in color, the reader is referred to the web version of this article at www.liebertpub.com/ars 


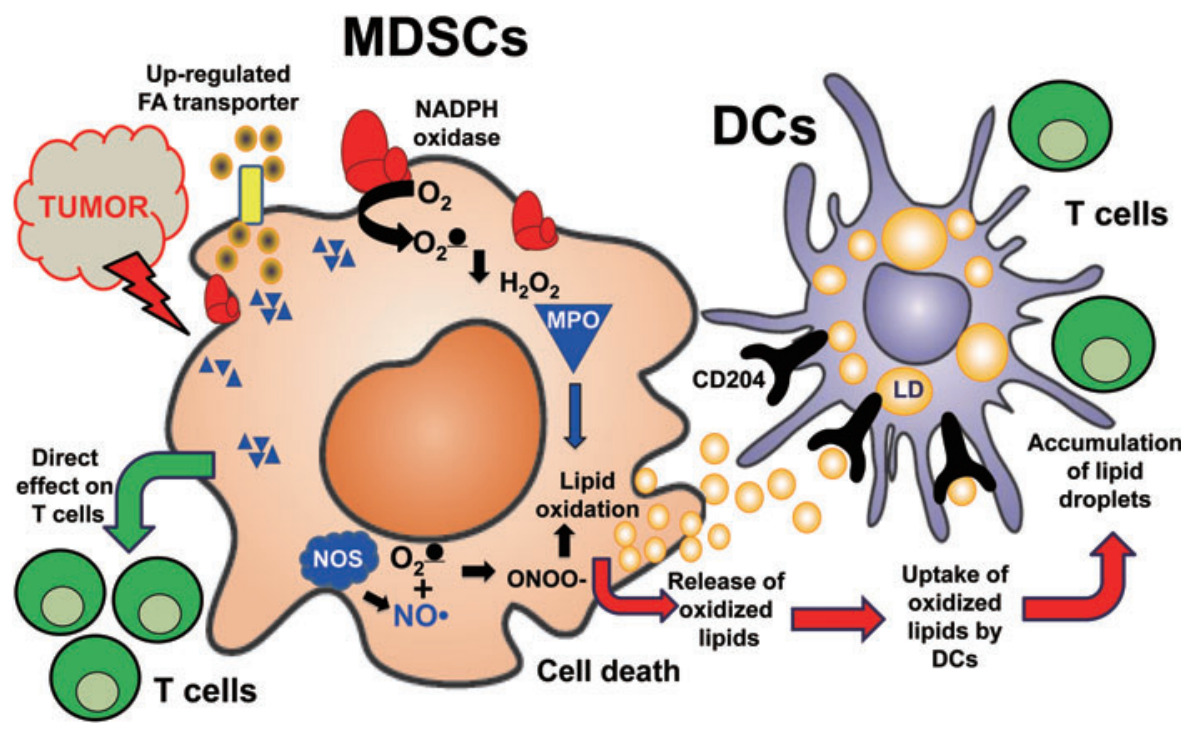

FIG. 16. A schema illustrating interactions of MDSC with dendritic cells in cancer. High pro-oxidant capacity of MDSC generates reactive oxygen species, and it triggers lipid oxidation and cell death. MDSC oxygenated lipids are taken up by DC where they are deposited in lipid droplets and disturb the process of antigen crosspresentation. DC, dendritic cells; MDSC, myeloid-derived suppressor cells. To see this illustration in color, the reader is referred to the web version of this article at www .liebertpub.com/ars
PE species. Among doubly oxygenated PE species, PE containing doubly oxygenated arachidonic acid (PE38:4$\mathrm{OOH}$ ), a ferroptotic death signal, predominantly accumulated in the ileum on day 5 after irradiation (Fig. 14B).

Overall, these data illustrate the complexity of lipid mediator metabolism and lipid mediator signaling triggered by TBI in a radiosensitive tissue (Fig. 15). Further insights into the generation and steady-state levels of these products may lead to identification of reliable indicators of $\gamma$-irradiation-induced responses in vivo as important targets for the discovery and development of radioprotectors and radiosensitizers.

\section{Concluding Remarks}

Aerobic multicellular life has enormously benefited from the emergence of PUFA lipids, due to at least two remarkable new propensities: (i) adaptive capacities to fine-tune lipid bilayer modifications to maximize the effectiveness of the membrane proteins, and (ii) elaborate an extraordinary rich language including millions of naive and oxidatively modified lipid molecules as words-signals. With regards to oxygenated, such as octadecanoids, eicosanoids, docosapenta- and docosahexanoids, numerous meaningful lipid mediators and their receptors controlling major functions of cells and tissues have been identified. In contrast, oxygenated PUFA esterified into phospholipid molecules have been mostly associated with oxidative stress, damage, and disease conditions and only recently emerged as important regulators of normal physiological processes. Of course, free PUFA and PUFA phospholipids may be closely linked via effective inter-conversions by reacylation and hydrolysis enzymatic reactions, respectively, as has been recently demonstrated for oxidized forms of mitochondrial oxygenated CLs (155). However, the most common pathways for the production of free PUFA lipid mediators are realized via initial hydrolysis of PUFA phospholipids by phospholipases $\mathrm{A}_{2}$ followed by subsequent enzymatic oxygenation reactions (110). Both direct oxygenation of PUFA phospholipids and esterification of oxygenated-free PUFA into phospholipids have been described as metabolic pathways generating meaningful signals $(3,52,53)$. The significance and importance of these two different forms of oxygenated lipids in multiple specific functions are the subjects of active research.

Although oxygenated phospholipids have been considered important sources of lipid mediators, the signaling by oxygenated PUFA-containing neutral lipids, particularly of triacyl and diacyl-glycerols, is an emerging new direction of oxidative lipidomics research $(2,63,102,116)$. Notably, aberrant oxidative metabolism of fatty acids commonly results in the accumulation of lipid droplets that may contain highly oxidizable PUFA-containing neutral lipids (102). The disturbances in neutral lipid metabolism may occur in many diversified conditions with their specific pathophysiological significance and mechanisms. For example, the profiles and activity of placental enzymes, receptors, and transporters defining the balance between free and esterified PUFAs determine the extent of maternal lipid transfer to the fetus strongly affecting the fetal fat accretion (45). In cancer, dysregulated lipid metabolism may be accountable for the distorted surveillance mechanisms and suppressed functions of immune cells over the growing tumor $(42,164)$. Recently, the important role of oxygenated neutral lipids-PUFA triacylglycerols and free PUFA - in the inhibited processing and cross-presentation of tumor antigens to $T$ cells by dendritic cells and the complex relationships of the latter with myeloid-derived suppressor cells has been documented (120) (Figs. 16 and 17).

Uninterrupted and effective exchange of information between different types of cells in the microenvironment is integral to the maintenance of normal tissue homeostasis. The danger signals that are generated by the multicellular communities inform the irreparable injury of a particular cell, and they lead to its elimination through one of multiple specific programmed cell death pathways - in line with the principle presented in the title of this work: "Only a life lived for others is worth living." More than a dozen of these programs and the respective types of cell death have been identified and associated with specific features of cellular injury $(19,34,47,68$, $93,162,168)$. Here, we focused on two pathways - apoptosis and ferroptosis - and demonstrated a very high specificity of phospholipid signaling by oxygenated species of CLs and 
A

FIG. 17. An example illustrating possible signaling roles of tryacylglycerol oxidation products (oxidatively truncated species) in mouse DCs grown in the presence of tumor explant supernatants. (A) A schema illustrating the major pathways leading to the formation of oxidatively truncated products from triacylglycerols containing 9-hydroperoxy-linoleic acid. (B) DC grown in TES accumulate higher levels of oxidatively truncated TAG than DC grown CM. Typical LC-MS spectra of TAG obtained from dendritic cells grown in $\mathrm{CM}$ (control CM) (a) and dendritic cells grown in TES (EL4 murine tumor cells) (b). Scatter plot of changes in the levels of TAG species in DC exposed to TES EL4 murine tumor cells ( $\log _{2}$ [fold-change] vs. significance $-\log _{10}$ [ $p$-value] $)(n=3)$ (c). The amount of various oxidatively truncated TAG molecular species containing 9-ONA in control dendritic cells and dendritic cells treated with TES (d). The data present as mean \pm $\mathrm{SD}, n=3, * p=0.023$ and $* * p=0.006$ versus control. MS/MS analysis revealed the presence of truncated TAGs at $\mathrm{m} / \mathrm{z} 738.6242, \mathrm{~m} /$ $\mathrm{z} 766.6557$, and $\mathrm{m} / \mathrm{z} 792.6870$ containing oxidatively truncated (9-ONA) - 16:0/16:1/ 9-ONA; C16:0/C18:1/9-ONA; and C18:1/ C18:1/9-ONA, in dendritic cells exposed to TES. 9-ONA, 9-oxo-nonanoic acid; CM, complete media; Lp-PLA ${ }_{2}$, lipoprotein phospholipase $\mathrm{A}_{2}$; TAG, triacylglycerols; TES, tumor explant supernatant. To see this illustration in color, the reader is referred to the web version of this article at www .liebertpub.com/ars

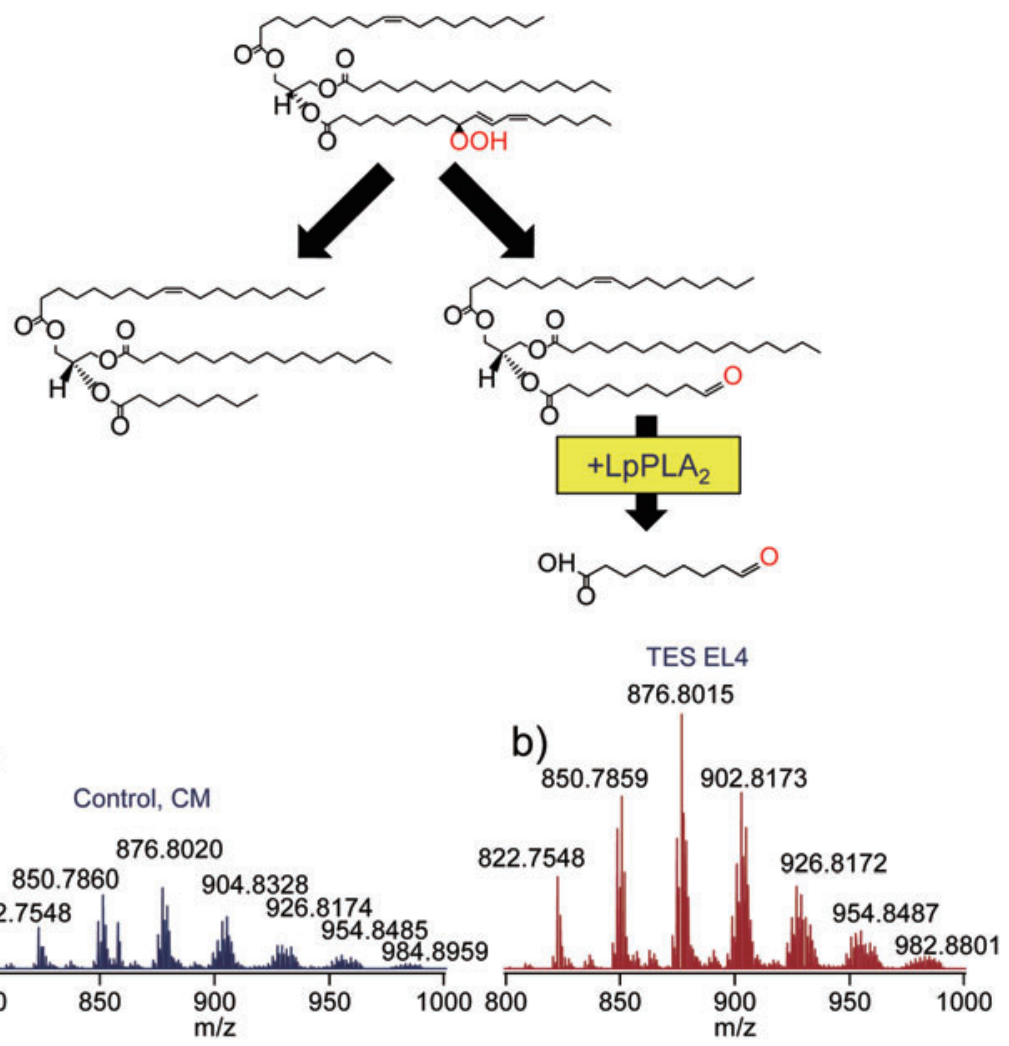

c)

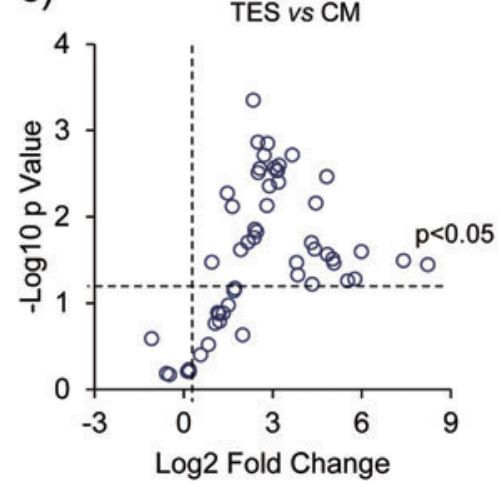

d)

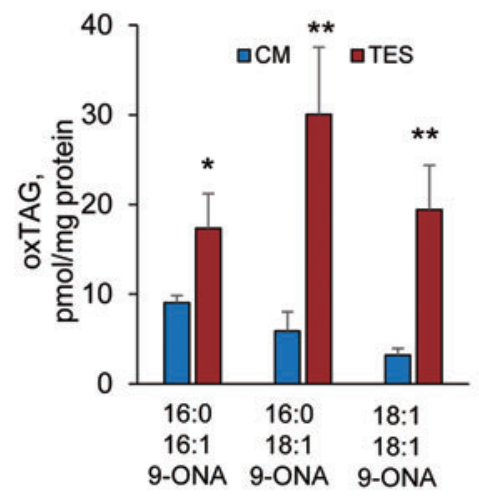

Molecular Species
PEs, respectively. Although the identification of these oxygenated lipid signals is an important step achieved through oxidative lipidomics, the molecular mechanisms of their action leading to specific features of cell membrane damage and penultimate executions of apoptotic and ferroptotic programs are still unclear.

A quantitative comparison of the lost PUFA PLs and detectable steady-state concentrations of PL oxidation products suggests that the latter represent only a fraction of the former. What is the fate of the "disappeared" oxygenated PLs? One of the possible explanations is that they form adducts, with the proteins, as has been discovered for electrophilic-free oxygenated PUFA products. For the electrophiles formed from free PUFA, some of the protein targets have been identified by LC-MS-based redox proteomics $(2,17)$. To the best of our knowledge, this has not been accomplished for the electrophiles produced from oxidatively modified (truncated) PLs. It is likely that one of the major reasons is their remarkable diversification minimizing hopes for success. Identification of only three oxygenated CLs and four oxygenated PEs as biomarkers of apoptotic and ferroptotic death signals, respectively, narrows the search for the potential modified proteins-the targets of covalent modification by the oxidatively truncated electrophiles derived from these CLox and PEox precursors.

Although the number of potential nucleophile-rich targets may be quite large, the knowledge obtained through global oxidative lipidomics combined with the specific conditions for triggering these two programs of cell demise creates optimistic prognosis for the next move toward oxidative lipoproteomic identification of the ultimate executors of cell death programs. 


\section{Acknowledgments}

This work was supported by NIH (P01HL114453, U19AI068021, NS076511, NS061817, CA165065, ES020693), and HFSP-RGP0013/2014, March of Dimes Pennsylvania, University of Pittsburgh Vascular Medicine Institute, the Barth Syndrome Foundation, Inc., and the Barth Syndrome Foundation of Canada.

\section{References}

1. Agbor TA, Demma ZC, Mumy KL, Bien JD, and McCormick BA. The ERM protein, ezrin, regulates neutrophil transmigration by modulating the apical localization of MRP2 in response to the SipA effector protein during Salmonella Typhimurium infection. Cell Microbiol 13: 2007-2021, 2011.

2. Aldini G, Domingues MR, Spickett CM, Domingues P, Altomare A, Sanchez-Gomez FJ, Oeste CL, and PerezSala D. Protein lipoxidation: detection strategies and challenges. Redox Biol 5: 253-266, 2015.

3. Aldrovandi M, Hinz C, Lauder SN, Podmore H, Hornshaw M, Slatter DA, Tyrrell VJ, Clark SR, Marnett LJ, Collins PW, Murphy RC, and O'Donnell VB. DioxolaneA3phosphatidylethanolamines are generated by human platelets and stimulate neutrophil integrin expression. Redox Biol 11: 663-672, 2017.

4. Arranz L, Fernandez C, Rodriguez A, Ribera JM, and De la Fuente M. The glutathione precursor N-acetylcysteine improves immune function in postmenopausal women. Free Radic Biol Med 45: 1252-1262, 2008.

5. Aryal B and Rao VA. Deficiency in cardiolipin reduces doxorubicin-induced oxidative stress and mitochondrial damage in human B-Lymphocytes. PLoS One 11: e0158376, 2016.

6. Ascenzi P, Coletta M, Wilson MT, Fiorucci L, Marino M, Polticelli F, Sinibaldi F, and Santucci R. Cardiolipincytochrome c complex: switching cytochrome $\mathrm{c}$ from an electron-transfer shuttle to a myoglobin- and a peroxidaselike heme-protein. IUBMB Life 67: 98-109, 2015.

7. Atkinson J, Kapralov AA, Yanamala N, Tyurina YY, Amoscato AA, Pearce L, Peterson J, Huang Z, Jiang J, Samhan-Arias AK, Maeda A, Feng W, Wasserloos K, Belikova NA, Tyurin VA, Wang H, Fletcher J, Wang Y, Vlasova, II, Klein-Seetharaman J, Stoyanovsky DA, Bayir H, Pitt BR, Epperly MW, Greenberger JS, and Kagan VE. A mitochondria-targeted inhibitor of cytochrome c peroxidase mitigates radiation-induced death. Nat Commun 2: 497, 2011.

8. Azzam EI, Jay-Gerin JP, and Pain D. Ionizing radiationinduced metabolic oxidative stress and prolonged cell injury. Cancer Lett 327: 48-60, 2012.

9. Bakan A, Kapralov AA, Bayir H, Hu F, Kagan VE, and Bahar I. Inhibition of peroxidase activity of cytochrome c: de novo compound discovery and validation. Mol Pharmacol 88: 421-427, 2015.

10. Bates S and Vousden KH. Mechanisms of p53-mediated apoptosis. Cell Mol Life Sci 55: 28-37, 1999.

11. Bayir H, Fadeel B, Palladino MJ, Witasp E, Kurnikov IV, Tyurina YY, Tyurin VA, Amoscato AA, Jiang J, Kochanek PM, DeKosky ST, Greenberger JS, Shvedova AA, and Kagan VE. Apoptotic interactions of cytochrome c: redox flirting with anionic phospholipids within and outside of mitochondria. Biochim Biophys Acta 1757: 648-659, 2006.
12. Bayir H, Tyurin VA, Tyurina YY, Viner R, Ritov V, Amoscato AA, Zhao Q, Zhang XJ, Janesko-Feldman KL, Alexander H, Basova LV, Clark RS, Kochanek PM, and Kagan VE. Selective early cardiolipin peroxidation after traumatic brain injury: an oxidative lipidomics analysis. Ann Neurol 62: 154-169, 2007.

13. Broadhurst CL, Wang Y, Crawford MA, Cunnane SC, Parkington JE, and Schmidt WF. Brain-specific lipids from marine, lacustrine, or terrestrial food resources: potential impact on early African Homo sapiens. Comp Biochem Physiol B Biochem Mol Biol 131: 653-673, 2002.

14. Chiurchiu V, Leuti A, Dalli J, Jacobsson A, Battistini L, Maccarrone M, and Serhan CN. Proresolving lipid mediators resolvin D1, resolvin D2, and maresin 1 are critical in modulating $\mathrm{T}$ cell responses. Sci Transl Med 8: 353ra111, 2016.

15. Chu CT, Bayir H, and Kagan VE. LC3 binds externalized cardiolipin on injured mitochondria to signal mitophagy in neurons: implications for Parkinson disease. Autophagy 10: 376-378, 2014.

16. Chu CT, Ji J, Dagda RK, Jiang JF, Tyurina YY, Kapralov AA, Tyurin VA, Yanamala N, Shrivastava IH, Mohammadyani $\mathrm{D}$, Qiang Wang $\mathrm{KZ}$, Zhu J, KleinSeetharaman J, Balasubramanian K, Amoscato AA, Borisenko G, Huang Z, Gusdon AM, Cheikhi A, Steer EK, Wang R, Baty C, Watkins S, Bahar I, Bayir H, and Kagan VE. Cardiolipin externalization to the outer mitochondrial membrane acts as an elimination signal for mitophagy in neuronal cells. Nat Cell Biol 15: 1197-1205, 2013.

17. Codreanu SG and Liebler DC. Novel approaches to identify protein adducts produced by lipid peroxidation. Free Radic Res 49: 881-887, 2015.

18. Cogliati S, Enriquez JA, and Scorrano L. Mitochondrial cristae: where beauty meets functionality. Trends Biochem Sci 41: 261-273, 2016.

19. Conrad M, Angeli JP, Vandenabeele P, and Stockwell BR. Regulated necrosis: disease relevance and therapeutic opportunities. Nat Rev Drug Discov 15: 348-366, 2016.

20. Crawford MA. The role of essential fatty acids in neural development: implications for perinatal nutrition. Am $J$ Clin Nutr 57: 703S-709S; discussion 709S-710S, 1993.

21. Crawford MA and Broadhurst CL. The role of docosahexaenoic and the marine food web as determinants of evolution and hominid brain development: the challenge for human sustainability. Nutr Health 21: 17-39, 2012.

22. Crawford MA, Costeloe K, Ghebremeskel K, Phylactos A, Skirvin L, and Stacey F. Are deficits of arachidonic and docosahexaenoic acids responsible for the neural and vascular complications of preterm babies? Am J Clin Nutr 66: 1032S-1041S, 1997.

23. Crawford MA, Doyle W, Leaf A, Leighfield M, Ghebremeskel K, and Phylactos A. Nutrition and neurodevelopmental disorders. Nutr Health 9: 81-97, 1993.

24. Crawford MA and Sinclair AJ. The limitations of whole tissue analysis to define linolenic acid deficiency. $J$ Nutr 102: 1315-1321, 1972.

25. Dalebroux ZD, Matamouros S, Whittington D, Bishop RE, and Miller SI. PhoPQ regulates acidic glycerophospholipid content of the Salmonella Typhimurium outer membrane. Proc Natl Acad Sci U S A 111: 1963-1968, 2014.

26. Dalli J, Colas RA, Quintana C, Barragan-Bradford D, Hurwitz S, Levy BD, Choi AM, Serhan CN, and Baron 
RM. Human sepsis eicosanoid and proresolving lipid mediator temporal profiles: correlations with survival and clinical outcomes. Crit Care Med 45: 58-68, 2017.

27. Dennis EA and Norris PC. Eicosanoid storm in infection and inflammation. Nat Rev Immunol 15: 511-523, 2015.

28. Di Mascio P, Murphy ME, and Sies H. Antioxidant defense systems: the role of carotenoids, tocopherols, and thiols. Am J Clin Nutr 53: 194S-200S, 1991.

29. Dixon SJ, Lemberg KM, Lamprecht MR, Skouta R, Zaitsev EM, Gleason CE, Patel DN, Bauer AJ, Cantley AM, Yang WS, Morrison B, III, and Stockwell BR. Ferroptosis: an iron-dependent form of nonapoptotic cell death. Cell 149: 1060-1072, 2012.

30. Dixon SJ, Winter GE, Musavi LS, Lee ED, Snijder B, Rebsamen M, Superti-Furga G, and Stockwell BR. Human haploid cell genetics reveals roles for lipid metabolism genes in nonapoptotic cell death. ACS Chem Biol 10: 1604-1609, 2015.

31. Doll S and Conrad M. Iron and ferroptosis: a still illdefined liaison. IUBMB Life 69:423-434, 2017.

32. Doll S, Proneth B, Tyurina YY, Panzilius E, Kobayashi S, Ingold I, Irmler M, Beckers $\mathrm{J}$, Aichler $\mathrm{M}$, Walch $\mathrm{A}$, Prokisch H, Trumbach D, Mao G, Qu F, Bayir H, Fullekrug J, Scheel CH, Wurst W, Schick JA, Kagan VE, Angeli JP, and Conrad M. ACSL4 dictates ferroptosis sensitivity by shaping cellular lipid composition. Nat Chem Biol 13: 91-98, 2017.

33. Domingues RM, Domingues P, Melo T, Perez-Sala D, Reis A, and Spickett CM. Lipoxidation adducts with peptides and proteins: deleterious modifications or signaling mechanisms? J Proteomics 92: 110-131, 2013.

34. Duprez L, Wirawan E, Vanden Berghe T, and Vandenabeele P. Major cell death pathways at a glance. Microbes Infect 11: 1050-1062, 2009.

35. Else PL, Turner N, and Hulbert AJ. The evolution of endothermy: role for membranes and molecular activity. Physiol Biochem Zool 77: 950-958, 2004.

36. Enriquez JA. Supramolecular organization of respiratory complexes. Annu Rev Physiol 78: 533-561, 2016.

37. Epperly MW, Sacher JR, Krainz T, Zhang X, Wipf P, Liang M, Fisher R, Li S, Wang H, and Greenberger JS. Effectiveness of analogs of the GS-nitroxide, JP4-039, as total body irradiation mitigators. In Vivo 31: 39-43, 2017.

38. Fenn JB. Electrospray wings for molecular elephants (Nobel lecture). Angew Chem Int Ed 42: 3871-3894, 2003.

39. Frankel EN. Lipid oxidation. Prog Lipid Res 19: 1-22, 1980.

40. Friedmann Angeli JP, Schneider M, Proneth B, Tyurina YY, Tyurin VA, Hammond VJ, Herbach N, Aichler M, Walch A, Eggenhofer E, Basavarajappa D, Radmark O, Kobayashi S, Seibt T, Beck H, Neff F, Esposito I, Wanke $\mathrm{R}$, Forster H, Yefremova O, Heinrichmeyer M, Bornkamm GW, Geissler EK, Thomas SB, Stockwell BR, O'Donnell VB, Kagan VE, Schick JA, and Conrad M. Inactivation of the ferroptosis regulator $\mathrm{Gpx} 4$ triggers acute renal failure in mice. Nat Cell Biol 16: 1180-1191, 2014.

41. Frohman MA. Role of mitochondrial lipids in guiding fission and fusion. J Mol Med (Berl) 93: 263-269, 2015.

42. Gabrilovich DI. Myeloid-derived suppressor cells. Cancer Immunol Res 5: 3-8, 2017.

43. Gaschler MM and Stockwell BR. Lipid peroxidation in cell death. Biochem Biophys Res Commun 482: 419-425, 2017.
44. Gijon MA, Riekhof WR, Zarini S, Murphy RC, and Voelker DR. Lysophospholipid acyltransferases and arachidonate recycling in human neutrophils. $\mathrm{J}$ Biol Chem 283: 30235-30245, 2008.

45. Gil-Sanchez A, Koletzko B, and Larque E. Current understanding of placental fatty acid transport. Curr Opin Clin Nutr Metab Care 15: 265-272, 2012.

46. Gorbunov NV and Sharma P. Protracted oxidative alterations in the mechanism of hematopoietic acute radiation syndrome. Antioxidants (Basel) 4: 134-152, 2015.

47. Green DR and Fitzgerald P. Just so stories about the evolution of apoptosis. Curr Biol 26: R620-R627, 2016.

48. Greenberger J, Kagan V, Bayir H, Wipf P, and Epperly M. Antioxidant approaches to management of ionizing irradiation injury. Antioxidants (Basel) 4: 82-101, 2015.

49. Gutteridge JM and Halliwell B. The measurement and mechanism of lipid peroxidation in biological systems. Trends Biochem Sci 15: 129-135, 1990.

50. Hamacher-Brady A and Brady NR. Mitophagy programs: mechanisms and physiological implications of mitochondrial targeting by autophagy. Cell Mol Life Sci 73: 775$795,2016$.

51. Hammerling BC and Gustafsson AB. Mitochondrial quality control in the myocardium: cooperation between protein degradation and mitophagy. J Mol Cell Cardiol 75: 122-130, 2014.

52. Hammond VJ, Morgan AH, Lauder S, Thomas CP, Brown S, Freeman BA, Lloyd CM, Davies J, Bush A, Levonen AL, Kansanen E, Villacorta L, Chen YE, Porter N, Garcia-Diaz YM, Schopfer FJ, and O'Donnell VB. Novel keto-phospholipids are generated by monocytes and macrophages, detected in cystic fibrosis, and activate peroxisome proliferator-activated receptor-gamma. J Biol Chem 287: 41651-41666, 2012.

53. Hammond VJ and O'Donnell VB. Esterified eicosanoids: generation, characterization and function. Biochim Biophys Acta 1818: 2403-2412, 2012.

54. Hannibal L, Tomasina F, Capdevila DA, Demicheli V, Tortora V, Alvarez-Paggi D, Jemmerson R, Murgida DH, and Radi R. Alternative conformations of cytochrome c: structure, function, and detection. Biochemistry 55: 407428, 2016.

55. Harman D. Aging and oxidative stress. J Int Fed Clin Chem 10: 24-27, 1998.

56. Hatch GM. Cardiolipin biosynthesis in the isolated heart. Biochem J 297 (Pt 1): 201-208, 1994.

57. Hatoum OA, Otterson MF, Kopelman D, Miura H, Sukhotnik I, Larsen BT, Selle RM, Moulder JE, and Gutterman DD. Radiation induces endothelial dysfunction in murine intestinal arterioles via enhanced production of reactive oxygen species. Arterioscler Thromb Vasc Biol 26: 287-294, 2006.

58. Horn T, Adel S, Schumann R, Sur S, Kakularam KR, Polamarasetty A, Redanna P, Kuhn H, and Heydeck D. Evolutionary aspects of lipoxygenases and genetic diversity of human leukotriene signaling. Prog Lipid Res 57: 13-39, 2015.

59. Hornstra G, Al MD, van Houwelingen AC, and Foremanvan Drongelen MM. Essential fatty acids in pregnancy and early human development. Eur J Obstet Gynecol Reprod Biol 61: 57-62, 1995.

60. Horrobin DF. Lipid metabolism, human evolution and schizophrenia. Prostaglandins Leukot Essent Fatty Acids 60: 431-437, 1999. 
61. Huang Z, Epperly M, Watkins SC, Greenberger JS, Kagan VE, and Bayir H. Necrostatin-1 rescues mice from lethal irradiation. Biochim Biophys Acta 1862: 850-856, 2016.

62. Huang Z, Jiang J, Tyurin VA, Zhao Q, Mnuskin A, Ren J, Belikova NA, Feng W, Kurnikov IV, and Kagan VE. Cardiolipin deficiency leads to decreased cardiolipin peroxidation and increased resistance of cells to apoptosis. Free Radic Biol Med 44: 1935-1944, 2008.

63. Hui SP, Sakurai T, Takeda S, Jin S, Fuda H, Kurosawa T, and Chiba H. Analysis of triacylglycerol hydroperoxides in human lipoproteins by Orbitrap mass spectrometer. Anal Bioanal Chem 405: 4981-4987, 2013.

64. Imai $\mathrm{H}$ and Nakagawa Y. Biological significance of phospholipid hydroperoxide glutathione peroxidase (PHGPX, GPx4) in mammalian cells. Free Radic Biol Med 34: 145169, 2003.

65. Ji J, Kline AE, Amoscato A, Samhan-Arias AK, Sparvero LJ, Tyurin VA, Tyurina YY, Fink B, Manole MD, Puccio AM, Okonkwo DO, Cheng JP, Alexander H, Clark RS, Kochanek PM, Wipf P, Kagan VE, and Bayir H. Lipidomics identifies cardiolipin oxidation as a mitochondrial target for redox therapy of brain injury. Nat Neurosci 15: 1407-1413, 2012.

66. Jiang J, Belikova NA, Hoye AT, Zhao Q, Epperly MW, Greenberger JS, Wipf P, and Kagan VE. A mitochondriatargeted nitroxide/hemigramicidin $\mathrm{S}$ conjugate protects mouse embryonic cells against gamma irradiation. Int $J$ Radiat Oncol Biol Phys 70: 816-825, 2008.

67. Jorgensen I, Lopez JP, Laufer SA, and Miao EA. IL-1beta, IL-18, and eicosanoids promote neutrophil recruitment to pore-induced intracellular traps following pyroptosis. Eur J Immunol 46: 2761-2766, 2016.

68. Jorgensen I, Rayamajhi M, and Miao EA. Programmed cell death as a defence against infection. Nat Rev Immunol 17: 151-164, 2017.

69. Kagan VE, Bayir A, Bayir H, Stoyanovsky D, Borisenko GG, Tyurina YY, Wipf P, Atkinson J, Greenberger JS, Chapkin RS, and Belikova NA. Mitochondria-targeted disruptors and inhibitors of cytochrome c/cardiolipin peroxidase complexes: a new strategy in anti-apoptotic drug discovery. Mol Nutr Food Res 53: 104-114, 2009.

70. Kagan VE, Bayir H, Tyurina YY, Bolevich SB, Maguire JJ, Fadeel B, and Balasubramanian K. Elimination of the unnecessary: intra- and extracellular signaling by anionic phospholipids. Biochem Biophys Res Commun 482: 482 490, 2017.

71. Kagan VE, Borisenko GG, Serinkan BF, Tyurina YY, Tyurin VA, Jiang J, Liu SX, Shvedova AA, Fabisiak JP, Uthaisang W, and Fadeel B. Appetizing rancidity of apoptotic cells for macrophages: oxidation, externalization, and recognition of phosphatidylserine. Am J Physiol Lung Cell Mol Physiol 285: L1-L17, 2003.

72. Kagan VE, Chu CT, Tyurina YY, Cheikhi A, and Bayir H. Cardiolipin asymmetry, oxidation and signaling. Chem Phys Lipids 179: 64-69, 2014.

73. Kagan VE, Fabisiak JP, Shvedova AA, Tyurina YY, Tyurin VA, Schor NF, and Kawai K. Oxidative signaling pathway for externalization of plasma membrane phosphatidylserine during apoptosis. FEBS Lett 477: 1-7, 2000.

74. Kagan VE, Jiang J, Huang Z, Tyurina YY, Desbourdes C, Cottet-Rousselle C, Dar HH, Verma M, Tyurin VA, Kapralov AA, Cheikhi A, Mao G, Stolz D, St Croix CM, Watkins S, Shen Z, Li Y, Greenberg ML, Tokarska-
Schlattner M, Boissan M, Lacombe ML, Epand RM, Chu CT, Mallampalli RK, Bayir H, and Schlattner U. NDPK-D (NM23-H4)-mediated externalization of cardiolipin enables elimination of depolarized mitochondria by mitophagy. Cell Death Differ 23: 1140-1151, 2016.

75. Kagan VE, Mao G, Qu F, Angeli JP, Doll S, Croix CS, Dar HH, Liu B, Tyurin VA, Ritov VB, Kapralov AA, Amoscato AA, Jiang J, Anthonymuthu T, Mohammadyani D, Yang Q, Proneth B, Klein-Seetharaman J, Watkins S, Bahar I, Greenberger J, Mallampalli RK, Stockwell BR, Tyurina YY, Conrad M, and Bayir H. Oxidized arachidonic and adrenic PEs navigate cells to ferroptosis. Nat Chem Biol 13: 81-90, 2017.

76. Kagan VE and Quinn PJ. Toward oxidative lipidomics of cell signaling. Antioxid Redox Signal 6: 199-202, 2004.

77. Kagan VE, Tyurin VA, Jiang J, Tyurina YY, Ritov VB, Amoscato AA, Osipov AN, Belikova NA, Kapralov AA, Kini V, Vlasova, II, Zhao Q, Zou M, Di P, Svistunenko DA, Kurnikov IV, and Borisenko GG. Cytochrome c acts as a cardiolipin oxygenase required for release of proapoptotic factors. Nat Chem Biol 1: 223-232, 2005.

78. Kappus $\mathrm{H}$ and Sies H. Toxic drug effects associated with oxygen metabolism: redox cycling and lipid peroxidation. Experientia 37: 1233-1241, 1981.

79. Kapralov AA, Kurnikov IV, Vlasova, II, Belikova NA, Tyurin VA, Basova LV, Zhao Q, Tyurina YY, Jiang J, Bayir H, Vladimirov YA, and Kagan VE. The hierarchy of structural transitions induced in cytochrome $\mathrm{c}$ by anionic phospholipids determines its peroxidase activation and selective peroxidation during apoptosis in cells. Biochemistry 46: 14232-14244, 2007.

80. Kapralov AA, Yanamala N, Tyurina YY, Castro L, Samhan-Arias A, Vladimirov YA, Maeda A, Weitz AA, Peterson J, Mylnikov D, Demicheli V, Tortora V, KleinSeetharaman J, Radi R, and Kagan VE. Topography of tyrosine residues and their involvement in peroxidation of polyunsaturated cardiolipin in cytochrome c/cardiolipin peroxidase complexes. Biochim Biophys Acta 1808: 21472155, 2011.

81. Kiebish MA, Han X, Cheng H, Lunceford A, Clarke CF, Moon H, Chuang JH, and Seyfried TN. Lipidomic analysis and electron transport chain activities in C57BL/6J mouse brain mitochondria. J Neurochem 106: 299-312, 2008.

82. Kitt JP, Bryce DA, Minteer SD, and Harris JM. Raman spectroscopy reveals selective interactions of cytochrome c with cardiolipin that correlate with membrane permeability. J Am Chem Soc 139: 3851-3860, 2017.

83. Klett EL, Chen S, Yechoor A, Lih FB, and Coleman RA. Long-chain acyl-CoA synthetase isoforms differ in preferences for eicosanoid species and long-chain fatty acids. J Lipid Res 58: 884-894, 2017.

84. Koppenol WH. The haber-weiss cycle-70 years later. Redox Rep 6: 229-234, 2001.

85. Kruiswijk F, Labuschagne CF, and Vousden KH. p53 in survival, death and metabolic health: a lifeguard with a licence to kill. Nat Rev Mol Cell Biol 16: 393-405, 2015.

86. Kuhn H, Banthiya S, and van Leyen K. Mammalian lipoxygenases and their biological relevance. Biochim Biophys Acta 1851: 308-330, 2015.

87. Lacombe ML, Tokarska-Schlattner M, Epand RF, Boissan M, Epand RM, and Schlattner U. Interaction of NDPK-D with cardiolipin-containing membranes: structural basis and implications for mitochondrial physiology. Biochimie 91: 779-783, 2009. 
88. Lagarde M, Bernoud-Hubac N, Calzada C, Vericel E, and Guichardant M. Lipidomics of essential fatty acids and oxygenated metabolites. Mol Nutr Food Res 57: 1347$1358,2013$.

89. LaVerne JA. OH radicals and oxidizing products in the gamma radiolysis of water. Radiat Res 153: 196-200, 2000 .

90. Leibowitz BJ, Wei L, Zhang L, Ping X, Epperly M, Greenberger J, Cheng $\mathrm{T}$, and $\mathrm{Yu} J$. Ionizing irradiation induces acute haematopoietic syndrome and gastrointestinal syndrome independently in mice. Nat Commun 5: 3494, 2014.

91. Lenaz G, Bovina C, D’Aurelio M, Fato R, Formiggini G, Genova ML, Giuliano G, Merlo Pich M, Paolucci U, Parenti Castelli G, and Ventura B. Role of mitochondria in oxidative stress and aging. Ann N Y Acad Sci 959: 199$213,2002$.

92. Lesnefsky EJ and Hoppel CL. Cardiolipin as an oxidative target in cardiac mitochondria in the aged rat. Biochim Biophys Acta 1777: 1020-1027, 2008.

93. Linkermann A, Stockwell BR, Krautwald S, and Anders HJ. Regulated cell death and inflammation: an autoamplification loop causes organ failure. Nat Rev Immunol 14: 759-767, 2014.

94. Louandre C, Ezzoukhry Z, Godin C, Barbare JC, Maziere JC, Chauffert B, and Galmiche A. Iron-dependent cell death of hepatocellular carcinoma cells exposed to sorafenib. Int J Cancer 133: 1732-1742, 2013.

95. Maguire JJ, Tyurina YY, Mohammadyani D, Kapralov AA, Anthonymuthu TS, Qu F, Amoscato AA, Sparvero LJ, Tyurin VA, Planas-Iglesias J, He RR, KleinSeetharaman J, Bayir H, and Kagan VE. Known unknowns of cardiolipin signaling: the best is yet to come. Biochim Biophys Acta 1862: 8-24, 2017.

96. Mao G, Qu F, St Croix CM, Tyurina YY, Planas-Iglesias J, Jiang J, Huang Z, Amoscato AA, Tyurin VA, Kapralov AA, Cheikhi A, Maguire J, Klein-Seetharaman J, Bayir H, and Kagan VE. Mitochondrial redox opto-lipidomics reveals mono-oxygenated cardiolipins as pro-apoptotic death signals. ACS Chem Biol 11: 530-540, 2016.

97. McClelland LJ, Mou TC, Jeakins-Cooley ME, Sprang SR, and Bowler BE. Structure of a mitochondrial cytochrome c conformer competent for peroxidase activity. Proc Natl Acad Sci U S A 111: 6648-6653, 2014.

98. Mejia EM, Nguyen H, and Hatch GM. Mammalian cardiolipin biosynthesis. Chem Phys Lipids 179: 11-16, 2014.

99. Mesulam MM. Large-scale neurocognitive networks and distributed processing for attention, language, and memory. Ann Neurol 28: 597-613, 1990.

100. Milazzo L, Tognaccini L, Howes BD, Sinibaldi F, Piro MC, Fittipaldi M, Baratto MC, Pogni R, Santucci R, and Smulevich G. Unravelling the non-native low-spin state of the cytochrome c-cardiolipin complex: evidence of the formation of a his-ligated species only. Biochemistry 56: 1887-1898, 2017.

101. Milic I, Kipping M, Hoffmann R, and Fedorova M. Separation and characterization of oxidized isomeric lipidpeptide adducts by ion mobility mass spectrometry. $J$ Mass Spectrom 50: 1386-1392, 2015.

102. Mohammadyani D, Tyurin VA, O’Brien M, Sadovsky Y, Gabrilovich DI, Klein-Seetharaman J, and Kagan VE. Molecular speciation and dynamics of oxidized triacylglycerols in lipid droplets: mass spectrometry and coarse-grained simulations. Free Radic Biol Med 76: 5360, 2014.

103. Moulder JE and Cohen EP. Future strategies for mitigation and treatment of chronic radiation-induced normal tissue injury. Semin Radiat Oncol 17: 141-148, 2007.

104. Mrsny RJ, Gewirtz AT, Siccardi D, Savidge T, Hurley BP, Madara JL, and McCormick BA. Identification of hepoxilin A3 in inflammatory events: a required role in neutrophil migration across intestinal epithelia. Proc Natl Acad Sci U S A 101: 7421-7426, 2004.

105. Muenzner J and Pletneva EV. Structural transformations of cytochrome c upon interaction with cardiolipin. Chem Phys Lipids 179: 57-63, 2014.

106. Mumy KL and McCormick BA. The role of neutrophils in the event of intestinal inflammation. Curr Opin Pharmacol 9: 697-701, 2009.

107. Myung SK, Kim Y, Ju W, Choi HJ, and Bae WK. Effects of antioxidant supplements on cancer prevention: metaanalysis of randomized controlled trials. Ann Oncol 21: 166-179, 2010.

108. Negida A, Menshawy A, El Ashal G, Elfouly Y, Hani Y, Hegazy Y, El Ghonimy S, Fouda S, and Rashad Y. Coenzyme Q10 for patients with parkinson's disease: a systematic review and meta-analysis. CNS Neurol Disord Drug Targets 15: 45-53, 2016.

109. Nicolaou A, Mauro C, Urquhart P, and Marelli-Berg F. Polyunsaturated fatty acid-derived lipid mediators and $\mathrm{T}$ cell function. Front Immunol 5: 75, 2014.

110. O'Donnell V and Murphy RC. Directing eicosanoid esterification into phospholipids. J Lipid Res 58: 837-839, 2017.

111. Oro J. Chemical synthesis of lipids and the origin of life. J Biol Phys 20: 135-147, 1994.

112. Packer L. Interactions among antioxidants in health and disease: vitamin E and its redox cycle. Proc Soc Exp Biol Med 200: 271-276, 1992.

113. Peyta L, Jarnouen K, Pinault M, Coulouarn C, Guimaraes C, Goupille C, de Barros JP, Chevalier S, Dumas JF, Maillot F, Hatch GM, Loyer P, and Servais S. Regulation of hepatic cardiolipin metabolism by TNFalpha: implication in cancer cachexia. Biochim Biophys Acta 1851: 1490-1500, 2015.

114. Pohl CH and Kock JL. Oxidized fatty acids as interkingdom signaling molecules. Molecules 19: 1273-1285, 2014.

115. Powell WS and Rokach J. Biosynthesis, biological effects, and receptors of hydroxyeicosatetraenoic acids (HETEs) and oxoeicosatetraenoic acids (oxo-ETEs) derived from arachidonic acid. Biochim Biophys Acta 1851: 340-355, 2015.

116. Proudfoot JM, Barden AE, Croft KD, Galano JM, Durand T, Bultel-Ponce V, Giera M, and Mori TA. F2-Isoprostanes in HDL are bound to neutral lipids and phospholipids. Free Radic Res 50: 1374-1385, 2016.

117. Radford IR. Initiation of ionizing radiation-induced apoptosis: DNA damage-mediated or does ceramide have a role? Int J Radiat Biol 75: 521-528, 1999.

118. Radford IR and Aldridge DR. Importance of DNA damage in the induction of apoptosis by ionizing radiation: effect of the scid mutation and DNA ploidy on the radiosensitivity of murine lymphoid cell lines. Int $J$ Radiat Biol 75: 143-153, 1999.

119. Rajagopalan MS, Gupta K, Epperly MW, Franicola D, Zhang X, Wang H, Zhao H, Tyurin VA, Pierce JG, Kagan 
VE, Wipf P, Kanai AJ, and Greenberger JS. The mitochondria-targeted nitroxide JP4-039 augments potentially lethal irradiation damage repair. In Vivo 23: 717726, 2009.

120. Ramakrishnan R, Tyurin VA, Veglia F, Condamine T, Amoscato A, Mohammadyani D, Johnson JJ, Zhang LM, Klein-Seetharaman J, Celis E, Kagan VE, and Gabrilovich DI. Oxidized lipids block antigen cross-presentation by dendritic cells in cancer. J Immunol 192: 2920-2931, 2014.

121. Reis A. Oxidative phospholipidomics in health and disease: achievements, challenges and hopes. Free Radic Biol Med 111: 25-37, 2017.

122. Ren M, Phoon CK, and Schlame M. Metabolism and function of mitochondrial cardiolipin. Prog Lipid Res 55: 1-16, 2014.

123. Rosca M, Minkler P, and Hoppel CL. Cardiac mitochondria in heart failure: normal cardiolipin profile and increased threonine phosphorylation of complex IV. Biochim Biophys Acta 1807: 1373-1382, 2011.

124. Rouzer CA and Marnett LJ. Endocannabinoid oxygenation by cyclooxygenases, lipoxygenases, and cytochromes P450: cross-talk between the eicosanoid and endocannabinoid signaling pathways. Chem Rev 111: 58995921, 2011.

125. Samhan-Arias AK, Ji J, Demidova OM, Sparvero LJ, Feng W, Tyurin V, Tyurina YY, Epperly MW, Shvedova AA, Greenberger JS, Bayir H, Kagan VE, and Amoscato AA. Oxidized phospholipids as biomarkers of tissue and cell damage with a focus on cardiolipin. Biochim Biophys Acta 1818: 2413-2423, 2012.

126. Santucci R, Sinibaldi F, Polticelli F, and Fiorucci L. Role of cardiolipin in mitochondrial diseases and apoptosis. Curr Med Chem 21: 2702-2714, 2014.

127. Savill J, Gregory C, and Haslett C. Cell biology. Eat me or die. Science 302: 1516-1517, 2003.

128. Schlame M. Cardiolipin synthesis for the assembly of bacterial and mitochondrial membranes. J Lipid Res 49: 1607-1620, 2008.

129. Schlame M. Cardiolipin remodeling and the function of tafazzin. Biochim Biophys Acta 1831: 582-588, 2013.

130. Schlame $M$ and Greenberg ML. Biosynthesis, remodeling and turnover of mitochondrial cardiolipin. Biochim Biophys Acta 1862: 3-7, 2017.

131. Schlame M and Haldar D. Cardiolipin is synthesized on the matrix side of the inner membrane in rat liver mitochondria. J Biol Chem 268: 74-79, 1993.

132. Schlame M and Hostetler KY. Solubilization, purification, and characterization of cardiolipin synthase from rat liver mitochondria. Demonstration of its phospholipid requirement. J Biol Chem 266: 22398-22403, 1991.

133. Schlattner U, Tokarska-Schlattner M, Epand RM, Boissan M, Lacombe ML, Klein-Seetharaman J, and Kagan VE. Mitochondrial NM23-H4/NDPK-D: a bifunctional nanoswitch for bioenergetics and lipid signaling. Naunyn Schmiedebergs Arch Pharmacol 388: 271-278, 2015.

134. Schlattner U, Tokarska-Schlattner M, Ramirez S, Tyurina YY, Amoscato AA, Mohammadyani D, Huang Z, Jiang J, Yanamala N, Seffouh A, Boissan M, Epand RF, Epand RM, Klein-Seetharaman J, Lacombe ML, and Kagan VE. Dual function of mitochondrial $\mathrm{Nm} 23-\mathrm{H} 4$ protein in phosphotransfer and intermembrane lipid transfer: a cardiolipin-dependent switch. J Biol Chem 288: 111-121, 2013.
135. Schneider M, Wortmann M, Mandal PK, Arpornchayanon W, Jannasch K, Alves F, Strieth S, Conrad M, and Beck H. Absence of glutathione peroxidase 4 affects tumor angiogenesis through increased 12/15-lipoxygenase activity. Neoplasia 12: 254-263, 2010.

136. Segawa $\mathrm{K}$ and Nagata $\mathrm{S}$. An apoptotic "Eat Me" signal: phosphatidylserine exposure. Trends Cell Biol 25: 639650, 2015.

137. Seiler A, Schneider M, Forster H, Roth S, Wirth EK, Culmsee C, Plesnila N, Kremmer E, Radmark O, Wurst W, Bornkamm GW, Schweizer U, and Conrad M. Glutathione peroxidase 4 senses and translates oxidative stress into 12/15-lipoxygenase dependent- and AIF-mediated cell death. Cell Metab 8: 237-248, 2008.

138. Shibata T. 15-Deoxy-Delta(1)(2),(1)(4)-prostaglandin J(2) as an electrophilic mediator. Biosci Biotechnol Biochem 79: 1044-1049, 2015.

139. Sies H. Strategies of antioxidant defense. Eur J Biochem 215: 213-219, 1993.

140. Sies H. Oxidative stress: oxidants and antioxidants. Exp Physiol 82: 291-295, 1997.

141. Skulachev VP, Antonenko YN, Cherepanov DA, Chernyak BV, Izyumov DS, Khailova LS, Klishin SS, Korshunova GA, Lyamzaev KG, Pletjushkina OY, Roginsky VA, Rokitskaya TI, Severin FF, Severina, II, Simonyan RA, Skulachev MV, Sumbatyan NV, Sukhanova EI, Tashlitsky VN, Trendeleva TA, Vyssokikh MY, and Zvyagilskaya RA. Prevention of cardiolipin oxidation and fatty acid cycling as two antioxidant mechanisms of cationic derivatives of plastoquinone (SkQs). Biochim Biophys Acta 1797: 878-889, 2010.

142. Slater TF. Lipid peroxidation. Biochem Soc Trans 10: 7071, 1982.

143. Smeitink J, van den Heuvel L, and DiMauro S. The genetics and pathology of oxidative phosphorylation. Nat Rev Genet 2: 342-352, 2001.

144. Spickett CM. The lipid peroxidation product 4-hydroxy-2nonenal: advances in chemistry and analysis. Redox Biol 1: 145-152, 2013.

145. Spickett CM and Pitt AR. Oxidative lipidomics coming of age: advances in analysis of oxidized phospholipids in physiology and pathology. Antioxid Redox Signal 22: 1646-1666, 2015.

146. Steinbrenner H, Speckmann B, and Klotz LO. Selenoproteins: antioxidant selenoenzymes and beyond. Arch Biochem Biophys 595: 113-119, 2016.

147. Steinhubl SR. Why have antioxidants failed in clinical trials? Am J Cardiol 101: 14D-19D, 2008.

148. Stoyanovsky DA, Huang Z, Jiang J, Belikova NA, Tyurin V, Epperly MW, Greenberger JS, Bayir H, and Kagan VE. A manganese-porphyrin complex decomposes $\mathrm{H}(2) \mathrm{O}(2)$, inhibits apoptosis, and acts as a radiation mitigator in vivo. ACS Med Chem Lett 2: 814-817, 2011.

149. Tappel AL. Protection against free radical lipid peroxidation reactions. Adv Exp Med Biol 97: 111-131, 1978.

150. Thorne-Lyman AL and Fawzi WW. Vitamin A and carotenoids during pregnancy and maternal, neonatal and infant health outcomes: a systematic review and metaanalysis. Paediatr Perinat Epidemiol 26 Suppl 1: 36-54, 2012.

151. Tyurin VA, Balasubramanian K, Winnica D, Tyurina YY, Vikulina AS, He RR, Kapralov AA, Macphee $\mathrm{CH}$, and Kagan VE. Oxidatively modified phosphatidylserines on the surface of apoptotic cells are essential phagocytic 
"eat-me" signals: cleavage and inhibition of phagocytosis by Lp-PLA2. Cell Death Differ 21: 825-835, 2014.

152. Tyurin VA, Tyurina YY, Jung MY, Tungekar MA, Wasserloos KJ, Bayir H, Greenberger JS, Kochanek PM, Shvedova AA, Pitt B, and Kagan VE. Mass-spectrometric analysis of hydroperoxy- and hydroxy-derivatives of cardiolipin and phosphatidylserine in cells and tissues induced by pro-apoptotic and pro-inflammatory stimuli. $J$ Chromatogr B Analyt Technol Biomed Life Sci 877: 28632872, 2009.

153. Tyurina YY, Kisin ER, Murray A, Tyurin VA, Kapralova VI, Sparvero LJ, Amoscato AA, Samhan-Arias AK, Swedin L, Lahesmaa R, Fadeel B, Shvedova AA, and Kagan VE. Global phospholipidomics analysis reveals selective pulmonary peroxidation profiles upon inhalation of single-walled carbon nanotubes. ACS Nano 5: 73427353, 2011.

154. Tyurina YY, Polimova AM, Maciel E, Tyurin VA, Kapralova VI, Winnica DE, Vikulina AS, Domingues MR, McCoy J, Sanders LH, Bayir H, Greenamyre JT, and Kagan VE. LC/MS analysis of cardiolipins in substantia nigra and plasma of rotenone-treated rats: implication for mitochondrial dysfunction in Parkinson's disease. Free Radic Res 49: 681-691, 2015.

155. Tyurina YY, Poloyac SM, Tyurin VA, Kapralov AA, Jiang J, Anthonymuthu TS, Kapralova VI, Vikulina AS, Jung MY, Epperly MW, Mohammadyani D, KleinSeetharaman J, Jackson TC, Kochanek PM, Pitt BR, Greenberger JS, Vladimirov YA, Bayir H, and Kagan VE. A mitochondrial pathway for biosynthesis of lipid mediators. Nat Chem 6: 542-552, 2014.

156. Tyurina YY, Tyurin VA, Epperly MW, Greenberger JS, and Kagan VE. Oxidative lipidomics of gammairradiation-induced intestinal injury. Free Radic Biol Med 44: 299-314, 2008.

157. Tyurina YY, Tyurin VA, Kapralova VI, Wasserloos K, Mosher M, Epperly MW, Greenberger JS, Pitt BR, and Kagan VE. Oxidative lipidomics of gamma-radiationinduced lung injury: mass spectrometric characterization of cardiolipin and phosphatidylserine peroxidation. Radiat Res 175: 610-621, 2011.

158. Tyurina YY, Tyurin VA, Kaynar AM, Kapralova VI, Wasserloos K, Li J, Mosher M, Wright L, Wipf P, Watkins S, Pitt BR, and Kagan VE. Oxidative lipidomics of hyperoxic acute lung injury: mass spectrometric characterization of cardiolipin and phosphatidylserine peroxidation. Am J Physiol Lung Cell Mol Physiol 299: L73L85, 2010.

159. Ullery JC and Marnett LJ. Protein modification by oxidized phospholipids and hydrolytically released lipid electrophiles: investigating cellular responses. Biochim Biophys Acta 1818: 2424-2435, 2012.

160. Urquhart P, Nicolaou A, and Woodward DF. Endocannabinoids and their oxygenation by cyclooxygenases, lipoxygenases and other oxygenases. Biochim Biophys Acta 1851: 366-376, 2015.

161. Ursini F, Maiorino M, and Forman HJ. Redox homeostasis: The Golden Mean of healthy living. Redox Biol 8: 205-215, 2016.

162. Vandenabeele P, Vandecasteele K, Bachert C, Krysko O, and Krysko DV. Immunogenic apoptotic cell death and anticancer immunity. Adv Exp Med Biol 930: 133-149, 2016.
163. Vasil'ev YV, Tzeng SC, Huang L, and Maier CS. Protein modifications by electrophilic lipoxidation products: adduct formation, chemical strategies and tandem mass spectrometry for their detection and identification. Mass Spectrom Rev 33: 157-182, 2014.

164. Veglia F and Gabrilovich DI. Dendritic cells in cancer: the role revisited. Curr Opin Immunol 45: 43-51, 2017.

165. Volinsky R, Cwiklik L, Jurkiewicz P, Hof M, Jungwirth P, and Kinnunen PK. Oxidized phosphatidylcholines facilitate phospholipid flip-flop in liposomes. Biophys $J$ 101: 1376-1384, 2011.

166. Wallgren M, Beranova L, Pham QD, Linh K, Lidman M, Procek J, Cyprych K, Kinnunen PK, Hof M, and Grobner G. Impact of oxidized phospholipids on the structural and dynamic organization of phospholipid membranes: a combined DSC and solid state NMR study. Faraday Discuss 161: 499-513; discussion 563-589, 2013.

167. Wang G, Bainbridge D, Martin J, and Cheng D. Nacetylcysteine in cardiac surgery: do the benefits outweigh the risks? A meta-analytic reappraisal. J Cardiothorac Vasc Anesth 25: 268-275, 2011.

168. Weinlich R, Oberst A, Beere HM, and Green DR. Necroptosis in development, inflammation and disease. Nat Rev Mol Cell Biol 18: 127-136, 2017.

169. Welchen E and Gonzalez DH. Cytochrome c, a hub linking energy, redox, stress and signaling pathways in mitochondria and other cell compartments. Physiol Plant 157: 310-321, 2016.

170. Williams JP and McBride WH. After the bomb drops: a new look at radiation-induced multiple organ dysfunction syndrome (MODS). Int J Radiat Biol 87: 851-868, 2011.

171. Wynn TA. Type 2 cytokines: mechanisms and therapeutic strategies. Nat Rev Immunol 15: 271-282, 2015.

172. Yang WS, Kim KJ, Gaschler MM, Patel M, Shchepinov MS, and Stockwell BR. Peroxidation of polyunsaturated fatty acids by lipoxygenases drives ferroptosis. Proc Natl Acad Sci U S A 113: E4966-E4975, 2016.

173. Yang WS, SriRamaratnam R, Welsch ME, Shimada K, Skouta R, Viswanathan VS, Cheah JH, Clemons PA, Shamji AF, Clish CB, Brown LM, Girotti AW, Cornish VW, Schreiber SL, and Stockwell BR. Regulation of ferroptotic cancer cell death by GPX4. Cell 156: 317-331, 2014.

174. Youle RJ and Narendra DP. Mechanisms of mitophagy. Nat Rev Mol Cell Biol 12: 9-14, 2011.

175. Zielinski ZA and Pratt DA. Lipid peroxidation: kinetics, mechanisms, and products. J Org Chem 82: 2817-2825, 2017.

176. Zilka O, Shan R, Li B, Friedmann Angeli JP, Griesser M, Conrad M, and Pratt DA. On the mechanism of cytoprotection by ferrostatin- 1 and liproxstatin- 1 and the role of lipid peroxidation in ferroptotic cell death. ACS Cent Sci 2017; DOI: 10.1021/acscentsci.7b00028.

Address correspondence to: Dr. Valerian E. Kagan

Department of Environmental and Occupational Health University of Pittsburgh Bridgeside Point

100 Technology Drive, Suite 350 Pittsburgh, PA 15219

E-mail: kagan@pitt.edu 
Date of first submission to ARS Central, April 19, 2017; date of final revised submission, August 10, 2017; date of acceptance, August 18, 2017.

$\begin{aligned} & \text { Abbreviations Used } \\ \text { 15-LO }= & 15 \text {-lipoxygenases } \\ 9-\mathrm{ONA}= & 9 \text {-oxo-nonanoic acid } \\ \text { AA-OOH-PE }= & 15 \text {-hydroperoxy-AA-PE } \\ \mathrm{AA}-\mathrm{PE}= & \text { arachidonoyl-phosphatidylethanolamine } \\ \mathrm{CL}= & \text { cardiolipin } \\ \mathrm{CLOX}= & \text { oxidized CL } \\ \mathrm{CM}= & \text { complete media } \\ \mathrm{cyt} c & =\text { cytochrome } c \\ \mathrm{DC}= & \text { dendritic cells } \\ \mathrm{DOPC}= & 1,2 \text {-dioleoyl-sn-glycero-3-phosphocholine } \\ \mathrm{HK} 2= & \text { human kidney epithelial } \\ \mathrm{IMM}= & \text { inner mitochondrial membranes } \\ \mathrm{LA}= & \text { linoleic acid } \\ \mathrm{LC} 3= & \text { light chain } 3 \\ \mathrm{LC}-\mathrm{PUF}= & \text { long-chain polyunsaturated fatty acid } \\ \mathrm{LO}= & \text { lipoxygenases }\end{aligned}$

LPCAT3 = lysophospholipid acyl transferase 3 LPE $=$ lyso-phosphatidylethanolamine species

Lp-PLA $\mathrm{P}_{2}=$ lipoprotein phospholipase $\mathrm{A}_{2}$ $\mathrm{LTB}_{4}=$ leukotriene $\mathrm{B}_{4}$

MD2 = myeloid differentiation protein 2

MDSC $=$ myeloid-derived suppressor cells

MLE $=$ mouse lung epithelial

MRP2 $=$ multidrug resistance-associated protein 2

$\mathrm{MS}=$ mass spectrometry

NDPK-D = nucleoside-diphosphate kinase D

$\mathrm{OMM}=$ outer mitochondrial membrane

$\mathrm{PE}=$ phosphatidylethanolamine

$\mathrm{PS}=$ phosphatidylserine

PUFA $=$ polyunsaturated fatty acids

ROS $=$ reactive oxygen species

$\mathrm{SD}=$ standard deviation

$\mathrm{TAG}=$ triacylglycerols

$\mathrm{TBI}=$ total body irradiation

TES $=$ tumor explant supernatant

TLCL $=$ tetra-linoleyl-CL

TLR $4=$ toll-like receptor 4 